(C) 2020 Elsevier Ltd. This manuscript version is made available under the CC-BY-NC-ND 4.0 license (http://creativecommons.org/licenses/by-nc-nd/4.0/)

Portable dehumidifiers condensed water: a novel matrix for the screening of semivolatile compounds in indoor air

M. Cobo, M. Ramil, R. Cela, I. Rodríguez*

Department of Analytical Chemistry, Nutrition and Food Sciences. Institute of Research on Chemical and Biological Analysis (IAQBUS). Universidade de Santiago de Compostela, 15782-Santiago de Compostela, Spain.

*corresponding author

e-mail: isaac.rodriguez@usc.es

Versión revisada del trabajo con mismo nombre publicado en la revista Chemosphere:

Referencia trabajo:

Chemosphere 251 (2020) 126346

https://doi.org/10.1016/j.chemosphere.2020.126346 
Highlights:

- Dehumidifier condensates contain qualitative information of indoor pollutants

- Above 140 compounds identified following a non-target data mining approach

- Variable condensate composition depending on the investigated environment

- Acceptable repeatability between samples obtained with different dehumidifiers

- Extraction efficiency correlated to Henry's law constant 


\section{Portable dehumidifiers condensed water: a novel matrix for the screening of semi- volatile compounds in indoor air}

M. Cobo, M. Ramil, R. Cela, I. Rodríguez*

Department of Analytical Chemistry, Nutrition and Food Sciences. Institute of Research on Chemical and Biological Analysis (IAQBUS). Universidade de Santiago de Compostela, 15782-Santiago de Compostela, Spain.

\section{Abstract}

The comprehensive identification of organic species existing in indoor environments is a key issue to understand their impact in human health. This study proposes the analysis of condensed water samples, collected with portable dehumidifiers, to characterize semivolatile compounds in the gas phase of confined areas. Water samples are concentrated by solid-phase extraction (SPE). The obtained extracts are analysed by gas chromatography (GC) time-of-flight mass spectrometry (TOF-MS), following a non-target screening data mining approach. In first term, spectra of deconvoluted compounds are compared with those in NIST low resolution library; thereafter, tentative identifications are verified using an inhouse database of accurate electron ionization (EI) MS spectra. Chromatographic (retention index) and spectral data are combined for unambiguous species identification. The potential of condensed water samples to reflect changes in the composition of indoor atmospheres, the match between data obtained using different dehumidifiers, and the relative concentration efficiency of condensed water compared to that attained by active sampling of moderate air volumes are discussed. A total of 141 semi-volatile compounds were identified (98 confirmed against authentic standards) in a set of 21 samples obtained from different homes and working places. This list contains more than 40 fragrances (including several potential allergens), solvents and intermediates in the production of polymeric materials, plasticizers and flame retardants.

Keywords: Indoor air; semi-volatile compounds; dehumidifiers; non-target screening; gas chromatography accurate mass spectrometry.

*corresponding author

e-mail: isaac.rodriguez@usc.es 


\section{Introduction}

Indoor environments contain rich, complex mixtures of organic chemicals which have been correlated with allergies, respiratory and dermal diseases (Araki et al. 2018; Steinemann and Goodman, 2019). Some of these compounds have a natural (human) origin (Liu et al., 2017); however, most of them are related to building materials, upholstery, personal care and household products (Lamas et al., 2010; Lucattini et al., 2018), and even with life habits (i.e. smoking and consumption of illict drugs) (Cecinato et al., 2017; Pandey and Kim, 2010). In addition to parent compounds released from above sources, their degradation products might also impair the quality of air in indoor environments (Wakayama et al., 2019).

Compounds released in indoor areas are distributed between dust particles and the gas phase. Analysis of dust is useful to evaluate human exposure through accidental ingestion, whilst the identification of compounds existing in air is required to understand inhalation exposure (Geens et al., 2009). Dust samples are available from domestic vacuum cleaners; however, air sampling requires the use of dedicated gadgets. Active sampling devices employ a vacuum pump forcing a stream of air through a trapping unit, usually consisting of a filter followed by a sorbent (Laboire et al., 2016). Their concentration efficiency depends on the sampling time, the flow of air through the trapping unit (measured using a flowmeter or volumetric counter), and the retention efficiency of the sorbent. Low density sorbents, offering a low pressure drop, such as polyurethane foam (PUF), permit high flow rates of air for effective concentration of semi-volatile compounds (Melymuk et al., 2016). Carbonaceous materials, Amberlite polymers and Tenax display a high affinity for volatile compounds (Hoang et al., 2017). In this case, the flow rate of air through the sorbent and the sampled volume are reduced in comparison with protocols dealing with semi-volatile compounds. To compensate for a lower enrichment factor, trapped compounds are totally transferred to a gas chromatography (GC) instrument through thermal desorption of the sorbent (Ramírez et al., 2010). Passive sampling devices, such as semipermeable membranes filled with liquid or solid sorbents (Gale et al., 2009), microextraction techniques 
(Esteve-Turillas et al., 2009) and PUF disks (Soheib and Harner, 2002) represent another option to investigate the presence of volatile compounds in confined atmospheres. In this approach, the uptake mass of a given compound depends on thermodynamic factors (affinity for the sorbent) and kinetic variables (diffusion rate from air to the active sorbent).

Portable dehumidifiers are appliances designed to reduce the concentration of water in air from interior environments. They incorporate a fan to create a stream of air, which passes first through a filter (to remove coarse particles), and then gets in contact with a cold region (usually the evaporator of a previously compressed cryogenic fluid), where water vapor condenses to be recovered in a draining tank. The high flow rate of air circulating through the dehumidifier, controlled by the turning speed of the fan, is expected to lead to a significant concentration of semi-volatile compounds in the condensed water. A previous study has described the presence of more than 40 compounds in condensed water obtained from the heater exchanger units of central air conditioning systems (Roll et al., 2015). Authors demonstrated the repeatability of chromatographic profiles for samples obtained from the same building in different dates; moreover, they showed how changes in daily activities affected the composition of water condensates (Roll et al., 2015). Unfortunately, central air conditioning facilities are not available everywhere, they do not provide information regarding the spatial distribution of organic compounds in different rooms from the same house, and the potential effect of each air conditioning facility in the composition of water condensates is not easy to evaluate.

The aim of this manuscript is to investigate comprehensively the range of organic compounds existing in condensed water samples obtained from portable dehumidifiers. To this end, samples were concentrated by solid-phase extraction (SPE). Thereafter, the SPE extracts were characterized by GC combined with accurate mass spectrometry (MS), based on a time-of-flight (TOF) instrument. Compounds identification was carried out by comparison of accurate electron ionization (EI) MS spectra of deconvoluted compounds with those included in the low resolution NIST database; followed by additional confirmation with 
an in-house database (personal compound database library, PCDL) of suspected targets (Castro et al. 2019; Gómez-Ramos et al., 2019). Concordance of results obtained using different dehumidifiers, placed in the same room, and major changes in the composition of drained water depending on the sampling place are reported. In addition, the concentration efficiencies attained using portable dehumidifiers and active sampling, of moderate air volumes, are compared and correlated with the properties of identified compounds.

\section{Material and methods}

\subsection{Solvents, standards and sorbents}

Ethyl acetate (AcOEt) (trace analysis grade) and methanol (MeOH) (LC gradient quality) were obtained from Merck (Darmstadt, Germany). Standards of compounds employed in the current study were provided by Sigma Aldrich (St. Louis, MO, USA), Riedel de Häen (Seelze, Germany) and Restek (Bellefonte, PA, USA). Compounds were acquired either as individual species, or as technical mixtures (case of some fragrances and other ingredients of personal care products). Stock solutions of each substance were prepared in $\mathrm{MeOH}$. Further dilutions and mixtures were made in AcOEt. The concentrations of standards employed to build the PCDL of accurate EI-MS spectra were in the range from 0.5 to $2 \mu \mathrm{g}$ $\mathrm{mL}^{-1}$. A standard mixture of $n$-alkanes $\left(\mathrm{C}_{8}-\mathrm{C}_{40}\right)$ in dichloromethane was provided by Supelco (Bellefonte, PA, USA). This solution was used to calculate the linear retention index (LRI) of compounds in chromatograms of sample extracts and those for standards included in the PCDL. LRI and accurate EI-MS spectra were employed for confirmation of tentative identifications derived from search of deconvoluted experimental spectra in the NIST database. PCB-30 (2,4,6-trichloro biphenyl) was used as injection standard, added to SPE extracts before GC-MS analysis.

OASIS HLB (200 mg) cartridges were purchased from Waters. This polymer was employed for the concentration of condensed water, and also as trapping sorbent for active air sampling. Dehumidifiers employed to obtain water samples from different indoor areas were purchased in local markets. They were furnished with a cryogenic fluid evaporator where 
water vapor condensates. A grid in the back side of these appliances served as a filter to limit the entrance of coarse particles into the evaporator unit. In some experiments, the grid was covered with glass fibre filters (GFF), pore size of $0.7 \mu \mathrm{m}$, provided by Sigma-Aldrich.

The membrane pump employed for active sampling of indoor air was purchased from Vaccubrand (model MD 4NT). It was connected to an HLB cartridge, followed by a rotameter. Air was sampled at a flow rate of $16.5 \mathrm{~L} \mathrm{~min}^{-1}$, similar to values considered in previous studies dealing with determination of fragrances (10 L min-1) (Lamas et al., 2010) and other semi-volatile compounds from indoor air (12 L min-1) (Laboire et al., 2016). Unless otherwise stated, the pump was operated $5 \mathrm{~h}$ to concentrate $5 \mathrm{~m}^{3}$ of air.

\subsection{Samples and sample preparation}

Dehumidifiers were placed in several indoor environments, including private houses and working places. After a given sampling time (5-12 h) condensed water samples were transferred to glass vessels, transported to the laboratory and stored at $4{ }^{\circ} \mathrm{C}$, for a maximum of $24 \mathrm{~h}$, before SPE extraction. Table 1 summarizes some data regarding the sampling places, and the codes assigned to the obtained samples. In brief, samples were taken in 10 different homes, two administrative buildings, a hair dressing in a shopping centre, and the research laboratory where SPE extractions were carried out. Additional information, including temperature and relative air humidity at the beginning of the sampling step, and the collected water volume are provided as supplementary material, Table S1.

Field blanks were prepared filling the drain vessel of dehumidifiers with ultrapure water. After a contact time of 12 hours, water was concentrated by SPE. Another set of blanks corresponded to SPE of ultrapure water without contact with dehumidifiers.

Water samples $(300 \mathrm{~mL}$ ) were concentrated using HLB cartridges previously conditioned with AcOEt, $\mathrm{MeOH}$ and ultrapure water (2 $\mathrm{mL}$ each). Following the concentration step, the sorbent was rinsed with $5 \mathrm{~mL}$ of ultrapure water, dried using a gentle stream of nitrogen and eluted with $2 \mathrm{~mL}$ of AcOEt. This extract was fortified with PCB-30 as injection standard, at 
$1000 \mathrm{ng} \mathrm{mL} \mathrm{m}^{-1}$, to check the stability in the responses of the GC-MS system. Potential breakthrough problems were investigated by passing the water sample $(300 \mathrm{~mL})$ through two cartridges connected in series. After the concentration step, they were disconnected and eluted separately.

HLB cartridges employed in active sampling experiments were conditioned with AcOEt (2 $\mathrm{mL}$ ). Thereafter, they were dried and wrapped in aluminium foil. During active air sampling experiments, the open edge of the cartridge was faced to floor (floor distance was $0.5 \mathrm{~m}$, similar to that existing in the air entrance of dehumidifiers) to prevent direct deposition of particulate matter on the frit above the sorbent. Breakthrough studies were carried out by spiking a standard mixture of fragrances, with different volatilities, in a plug of glass wool placed inside the barrel of the SPE cartridge, above the sorbent. In these experiments, $a 2^{\text {nd }}$ cartridge was connected in series. After sampling a given volume of air, cartridges were eluted separately with $2 \mathrm{~mL}$ of ethyl acetate. The plug of glass wool was sonicated with the same volume of solvent for $5 \mathrm{~min}$. In order to compare the range of compounds concentrated using active sampling and dehumidifiers, both systems were simultaneously operated in the same room.

\subsection{GC-MS system and data analysis}

Identification of compounds in indoor air related extracts was performed with a GC-QTOFMS instrument, obtained from Agilent (Wilmington, DE, USA). The system was comprised of a 7890A gas chromatograph connected to a 7200 QTOF MS spectrometer, which was furnished with an El source. The TOF was operated in the $2 \mathrm{GHz}$ mode, offering typical mass resolution values (FWHM) of 6500 at $\mathrm{m} / \mathrm{z}$ 131. The GC-QTOF-MS system was employed in the single MS mode, that is, as a GC-TOF-MS instrument. MS spectra were obtained at $2.5 \mathrm{~Hz}$ (5430 scans accumulated per spectrum) in the range of $\mathrm{m} / \mathrm{z}$ values from 40 to 600 . The $m / z$ axis in the mass analyser was automatically recalibrated, every 3 injections, by infusion of perfluorotributyl amine (PFTBA) in the El source. 
Two different columns were tested for the separation of compounds exiting in SPE extracts. They were a BP-5 MS (30 $\mathrm{m} \times 0.25 \mathrm{~mm}$ i.d., $0.25 \mu \mathrm{m}$ film thickness) and a DB-WAXETR one (30 $\mathrm{m} \times 0.25 \mathrm{~mm}$ i.d., $0.5 \mu \mathrm{m}$ film thickness). Both were acquired from Agilent. The carrier gas (Helium) flow rate was $1.2 \mathrm{~mL} \mathrm{~min}^{-1}$. Standards and sample extracts $(2 \mu \mathrm{L})$ were injected in the splitless mode, with the injector maintained at $260^{\circ} \mathrm{C}$. The splitless time and the split flow were $1 \mathrm{~min}$ and $50 \mathrm{~mL} \mathrm{~min}^{-1}$, respectively. The quadrupole and the El source temperatures were $150{ }^{\circ} \mathrm{C}$ and $230^{\circ} \mathrm{C}$, respectively. Two different oven temperature programs were employed. For the BP-5 column the gradient was $50^{\circ} \mathrm{C}(1 \mathrm{~min})$, rated at 10 ${ }^{\circ} \mathrm{C} \mathrm{min}^{-1}$ to $290{ }^{\circ} \mathrm{C}$ (15 min). When using the DB-WAXETR one, temperature varied as follows: $60^{\circ} \mathrm{C}(1 \mathrm{~min}), 1^{\text {st }}$ rate at $5^{\circ} \mathrm{C} \mathrm{min}^{-1}$ to $220^{\circ} \mathrm{C}, 2^{\text {nd }}$ rate at $20^{\circ} \mathrm{C} \mathrm{min}^{-1}$ to $240^{\circ} \mathrm{C}(15$ $\min )$. The temperature of the transfer line between the GC and the MS spectrometer was the same as the upper value employed with each column.

The MassHunter software was used to control the acquisition parameters in the GC-QTOFMS system and to process the obtained data. MassHunter Qualitative software (version B.08.00) was employed during inspection of raw GC-TOF-MS chromatograms, to extract the accurate El-MS spectra of standards and to transfer these spectra to a customized PCDL. In addition to accurate spectra, the PCDL database included LRI values.

Deconvolution of chromatograms obtained for indoor air related samples was carried out using the Unknowns Analysis (UA) function (based on the SureMass algorithm), integrated in the MassHunter Quantitative software (version B.08.00). Responses of deconvoluted species (peak areas corrected with that obtained for PCB30) were employed to evaluate the severity of contamination problems in procedural blanks, to compare the relative efficiencies of active air sampling versus concentrated dehumidifier water samples, to investigate the responses obtained for a given compound depending on the sampling place, and to evaluate the agreement between data obtained with different dehumidifiers. 
The MS Search ( $v$. 2.3) software was used to manage the spectra compiled in the NIST17 low resolution EI-MS library, and to calculate the theoretical $\mathrm{m} / \mathrm{z}$ ratios of fragment ions with known structures, using the NIST-MS interpreter tool, in this database.

The workflow for the non-target identification of pollutants in sample extracts has been described in detail in a previous publication (Castro et al., 2019). In brief, it involves deconvolution of raw GC-TOF-MS chromatograms, followed by spectral comparison with the low resolution NIST17 and the accurate PCDL libraries. The $2^{\text {nd }}$ database was updated continuously, taking into account tentative identifications derived from comparison with the NIST database. A scheme of the employed workflow is provided as supplementary information, Fig. S1. Currently, the created PCDL contains 265 inputs of volatile and semivolatile species.

\section{Results and discussion}

\subsection{Preliminary experiments}

A typical chromatogram obtained with the DB-WAXETR column for dehumidifier condensed water is provided as supplementary information, Fig. S2A. One of the latter, intense eluting peaks corresponded to dibutyl phthalate (DBP). Less volatile species, such as di(ethylhexyl) phthalate, tri-(butoxyethyl) phosphate, octocrylene and certain dyes (such as indigo), which are recognized as ubiquitous in dust from indoor areas (Castro et al., 2019; Fromme et al., 2004) were absent in this chromatogram. In order to verify that these less volatile compounds did not remain inside the employed column, the same extract was injected in the BP5-MS column, using a faster gradient and also a higher final temperature (290 ${ }^{\circ} \mathrm{C}$ versus $240{ }^{\circ} \mathrm{C}$ in the DB-WAXETR). DBP was again the latter intense peak in the BP-5 chromatogram, Fig. S2B. Thus, either less volatile species are mostly associated to indoor particles instead of to the gas phase (Weschler and Nazaroff, 2014), or they are not concentrated in condensed water samples. So, the more retentive and higher selectivity Carbowax-type column was selected for the rest of the study. 
As regards SPE of dehumidifier water, considering a sample volume of $300 \mathrm{~mL}$, rich chromatographic records (Fig. S2) were obtained without noticing breakthrough problems during the concentration step, just traces of some carboxylic acids were found in the security SPE cartridge (their peak areas represented between 1 and $2 \%$ of those observed in the extract from the first cartridge, figure not shown). Condensed water samples were concentrated without previous filtration to minimize the risk of losing any compound recovered from the indoor atmospheres. AcOEt was used for the elution of SPE cartridges considering its medium polarity and compatibility with GC-MS analysis. A volume of $2 \mathrm{~mL}$ was enough to recover species retained in the SPE sorbent.

The coarse grid of dehumidifiers might lead to the presence of dust particles in the drained water. Consequently, compounds in SPE extracts might correspond to species existing in the vapor phase, but also to those solubilised from dust particles. To investigate this possibility some experiments were carried out fitting a GFF filter behind the coarse grid of the dehumidifier. After operating the system for $48 \mathrm{~h}$, filters were sonicated with ethyl acetate and the extract concentrated to $2 \mathrm{~mL}$. The corresponding chromatograms were similar to those obtained for blank filters. Moreover, no significant peaks were noticed in the filter extract compared to those in the chromatogram of condensed water (Fig. S3). So, the stream of air created by the fan of the dehumidifier does not introduce particulate matter with a size larger than the cut-off of the filter $(0.7 \mu \mathrm{m})$ in the cooling unit of the system.

Efficiency of the HLB polymer to trap volatile compounds during active sampling $\left(16.5 \mathrm{~L} \mathrm{~min}^{-}\right.$ ${ }^{1}$ ) of indoor air was investigated with a mixture of 16 terpenes with different volatilities (their chromatographic retention times varied from $7.81 \mathrm{~min}$ for limonene to $30.54 \mathrm{~min}$ for carvacrol, see Table S2). Experiments were performed as described in section 2.2. After sampling $5 \mathrm{~m}^{3}$ of air, the extracted ion chromatograms (EIC), mass window $2 \mathrm{mDa}$, for their more representative ions (Table S2) corresponding to the glass wool plug, the retention and the security HLB cartridges were compared. Compounds were noticed only in the extract from the retention cartridge. 


\subsection{Database of accurate EI-MS spectra}

Mass accuracy of the GC-El-TOF-MS system employed in this study (first generation of Agilent TOF combined with GC) was in the range of $0.002 \mathrm{Da}$, equivalent to relative mass errors from 20 to $6.7 \mathrm{ppm}$ for ions with $\mathrm{m} / \mathrm{z}$ ratios in the range from 100 to 300 . Although these errors have been lowered by $2^{\text {nd }}$ generation TOF instruments (Stupak et al., 2018), and particularly by Orbitrap mass analyser (Gómez-Ramos et al., 2019), they sufficed to discriminate between ions with different empirical formula (considering $\mathrm{C}, \mathrm{H}, \mathrm{O}$ and $\mathrm{N}$ as their elements) and same nominal $m / z$ values.

During non-target analysis of complex samples, ions from two or more compounds are often merged under the same chromatographic peak; thus, spectral deconvolution is mandatory previously to compounds identification. Even after deconvolution, more often than desired, spectral data alone are not enough for the unambiguous identification of a given compound. Fig. 1A depicts a region of a deconvoluted compounds chromatogram. Spectra assigned to peaks in blue are shown in Fig. $1 \mathrm{~B}$ and $1 \mathrm{C}$, whilst the accurate spectrum for the best candidate (benzaldehyde) appears in Fig. 1D. The normalized scores (0-100) corresponding to the match of deconvoluted spectra with that recorded for benzaldehyde remained above 90 in both cases (Fig. 1B and 1C); moreover, the differences with $m / z$ values of ions in the PCDL spectra of benzaldehyde were lower than $1.3 \mathrm{mDa}$ (absolute value, Fig. 1D). Thus, without using chromatographic data (retention times or LRI) it would be practically impossible to discriminate which of the two peaks corresponds to benzaldehyde. In this case, the component at 15.97 min matched the LRI of benzaldehyde. Another example of compounds with practically identical El-MS spectra are the fragrances linalool $\left(\mathrm{C}_{10} \mathrm{H}_{18} \mathrm{O}\right.$, CAS number 78-70-6) and linalyl acetate $\left(\mathrm{C}_{12} \mathrm{H}_{20} \mathrm{O}_{2}\right.$, CAS number 115-95-7), Fig. S4A and S4B. In the latter case, the molecular ion $\left(\mathrm{M}^{+}\right)$is absent and most fragment ions (Fig. S4A) match those in the spectrum of linalool. Additional problematic cases are positional isomers. Very often, they show practically identical EI-MS spectra, as they are the cases of 
ethylbenzene and xylenes, di-butyl and di-isopropyl phthalates, thymol and carvacrol (Fig. S4C and D).

In order to overcome limitations reported in the previous paragraph, the PCDL was implemented with LRI values. Thus, positive identifications were based on spectral and LRI matches between deconvoluted compounds in extracts from indoor air-related samples and the PCDL database. The minimum normalized score (0-100) for the spectral match was set at 70 , and the maximum difference with database retention time $10 \mathrm{~s}$ (equivalent to a variation in LRI values of $8-10$ units). $A 3^{\text {rd }}$ requirement for a positive identification was a maximum relative error of $20 \mathrm{ppm}$ for any intense ion in the deconvoluted spectra compared to that in the PCDL spectrum of the candidate. These three conditions were verified by the Unknowns Analysis software during library search of deconvoluted components. Despite the restriction in the retention time window, in case of some isomeric species with very close retention times, such as the diastereomers of galaxolide, or $m$-xylene and $p$-xylene, revision of identities assigned by Unknowns Analysis was required.

\subsection{Dehumidifiers as samplers of semi-volatile compounds from indoor areas}

The chromatograms of dehumidifier water samples contained a high number of peaks related to species existing in indoor air (Fig. S2 and Fig. 1); however, in order to demonstrate the usefulness of this matrix to characterize the composition of indoor air, several features need to be considered. Firstly, it is necessary to check that compounds in condensed water are not contaminants introduced by dehumidifiers. Changes in the composition of the indoor environment must be reflected in the presence of new chromatographic peaks, and/or in variations in their response intensities in dehumidifier water extracts. In addition, similar chromatographic profiles should be obtained for the same environment when using different dehumidifiers.

In general, the chromatograms of procedural blanks were very similar to those obtained for SPE of ultrapure water, not in contact with dehumidifier draining tanks. However, for two of 
the tested dehumidifiers we found traces of tris (1,3-dichloro-2-propyl) phosphate (TCPP) and tributyl acetylcitrate in procedural blanks, so these devices were not used in further experiments. In addition to substances released from the draining vessel, the stream of air and the condensed water drops might release organic compounds from other elements of dehumidifiers before reaching the draining vessel. Although this problem is difficult to detect, we have compared the normalized responses (peak area divided by the peak area of PCB30) for a series of potentially problematic species (plasticizers, flame retardants, curing agents, fragrances...) in the extracts of water samples taken, with the same dehumidifier, in the living room from 6 different homes. Responses of selected compounds showed significant variations (in some cases up to 10-fold) depending on the sampling site, Fig. S5. Thus, if occurs, the release of above compounds from the dehumidifier unit would not mask variations among samples obtained from different environments.

Fig. 2 shows the ratio of responses obtained for selected compounds in the extracts from two water samples obtained from the same room ( $46 \mathrm{~m}^{3}$ volume). Samples were taken with the same dehumidifier, before and after installing an air freshener in the room (5 $\mathrm{m}$ distance from the dehumidifier). In addition to water extracts, the content of the freshener was diluted (105-fold dilution with AcOEt) and injected in the GC-TOF-MS system. In case of species not detected in the diluted freshener solution, response ratios from 0.8 to 1.2 were obtained, Fig. 2A. On the contrary, for compounds found in the freshener liquid, their responses increased between 2 and 62 times in the sample obtained after activation of the air aromatization device, Fig. 2B.

The effect of the dehumidifier device in the composition of condensed water samples was investigated operating simultaneously two different appliances in the same room. Chromatograms obtained at sampling point S21 (Table 1) are shown in Fig. 3A. The volumes of water recovered by each instrument differed around 20\%; however, similar chromatographic profiles were observed for both extracts. Fig. 3B shows the correlation plot between responses (logarithms of peak areas) for 50 identified compounds (after 
deconvolution and comparison with the PCDL) in the chromatograms for both samples. An acceptable correlation (determination coefficient, $\mathrm{R}^{2}, 0.959$ ) was observed; moreover, the slope of the plot (0.996) was close to the unit. Fig. $3 \mathrm{C}$ shows the equivalent plot for a second pair of dehumidifiers operating at sampling point S3. In this case, the graph compares the responses obtained for 70 positive identifications.

3.4. Comprehensive identification of semi-volatile compounds in dehumidifier water samples

The list of substances identified in dehumidifier water from the 21 sampling points considered in the current study (Table 1 ) is compiled in Tables $2 \mathrm{~A}$ and $2 \mathrm{~B}$. Compounds are classified attending to their applications (in most cases same species present different uses), and sorted accordingly to their increasing LRI values. Compounds detected in procedural blanks were included in the above tables only when their responses stayed above 10-times that observed in the procedural blank of the corresponding dehumidifier. Species such as toluene, styrene and dimethyl sulfoxide were ubiquitous in condensed water samples, however, they did not satisfy the above requirement; thus, they are not included in the list of positive identifications. Table 2A gathers compounds with applications as fragrances and flavors. They are usually incorporated in personal care, cleaning and other household products. Some of them are natural products whose empirical formulae derive from that of terpene $\left(\mathrm{C}_{10} \mathrm{H}_{16}\right)$, with one or two atoms of oxygen and variations in the number of unsaturated bonds. In other cases, they show a phenolic structure, as it is the case of salicylates, vanillin, eugenol and thymol. The list includes also synthetic musks, such as galaxolide and tonalide. Many compounds in Table 2A have been included in the list of potential contact allergens (Shibuta et al., 2016).

Regarding substances compiled in Table 2B, most of them belong to the category of solvents and intermediates in the production of high volume chemicals, followed by those used as preservatives and plasticizers. Within the first group, 2-ethyl-1-hexanol was ubiquitous in the processed samples. This compound can be released from polymeric materials; moreover, it can arise from hydrolysis of di-ethylhexyl phthalate (Wakayama et al., 2019), which has been 
quantified in indoor dust at high concentrations (Castro et al, 2019). Another intermediate often noticed in samples was cyclohexanone, which is involved in the polyurethane foams (Glowacz-Crerwonka, 2017). Likely, phenol and aniline are released from adhesives, paints and cleaning fluids (Palmiotto et al., 2001). The most probable sources of compounds integrated in the category of preservatives are again personal and household products. The list of plasticizers whose presence was confirmed in dehumidifier water samples includes four phthalates, two citrates, a diisobutyrate (2,2,4-trimethyl-1,3-pentanediol diisobutyrate; TXIB) and diacetin. All of them are high production volume chemicals widely employed in building materials, and they have been previously detected in indoor air (Lucattini et al., 2018; Ueta et al., 2019).

Table 3 summarizes a list of 43 compounds tentatively identified (not confirmed by injection of authentic standards) in the processed samples. Compounds in this table showed spectral match scores higher than $90 \%$ when their experimental accurate MS spectra are compared with those in the NIST database. Moreover, the difference between $\mathrm{m} / \mathrm{z}$ ratios in the deconvoluted spectra and the calculated values for ions with known structures in the NIST database remained below $2 \mathrm{mDa}$, at least for two intense fragment ions. When available, experimental LRI values of tentative identifications were compared with those obtained from Chemspider database (http://www.chemspider.com/), or directly for Carbowax-type columns in previous studies (Moniruzzaman et al., 2014). Most of them show similar applications to positive identifications compiled in Tables $2 \mathrm{~A}$ and $2 \mathrm{~B}$. The larger families of compounds in Table 3 are benzene derivatives, carboxylic acids of natural origin, and several of their esters with industrial applications as plasticizers (particularly those of phthalic, hexanoic and isobutyric acid), glycols and terpene derivatives. Some compounds listed in Table 3 are closely related to those positively identified in Table 2. An example is 2-(methylthio) benzothiazole, which has been reported together with benzothiazole in vehicle tires (Zhang et al., 2018). Another case corresponds to the isomers of 1,3-pentanediol, 2,2,4-trimethylisobutyrate (Texanol) with similar applications to TXIB (Ueta et al., 2019). 
Table 1 shows the identities assigned to the three most intense peaks in the chromatograms for condensed water samples from the 21 sampling sites involved in the current study. At least one plasticizer was within the above ranking for 14 out of 21 samples. Within the group of personal care and cleaning products, 2-phenoxyethanol was among the three most intense peaks in 5 sites. Nonanoic acid and diethylene glycol butyl ether were also often identified in the ranking of most intense peaks. Comparison of data for samples obtained at home 1 (sample codes S1, S2, S3, S4 and S5) revealed changes in the identities of the most intense chromatographic peaks between kitchen and garage (S4 and S17, respectively) with the other investigated rooms (S1, S2 and S3). Sample code S10 was obtained from the home of a smoker. In this case, the most intense chromatographic peak was identified as nicotine. In summary, even the major compounds in dehumidifier water extracts varied depending on the sampling area.

\subsection{Dehumidifier condensed water versus active air sampling}

Data in previous sections show that condensed water samples contain a cocktail of organic compounds potentially related with on-going activities, building materials and life style in indoor areas. The question is whether the qualitative information provided by dehumidifiers and active sampling are somehow correlated, or not. The raw chromatograms corresponding to active sampling (16.5 $\left.\mathrm{L} \mathrm{min}^{-1}\right)$ for $5 \mathrm{~h}$ through a HLB cartridge, and after concentration of condensed water sample obtained from a portable dehumidifier, both operating simultaneously in the same room, are shown in Fig. S6. The first part of the chromatogram for active sampling contains more intense peaks than those observed for condensed water (Fig. S6A). On the other hand, the latter chromatogram is richer in number and intensity of peaks with retention times above $17 \mathrm{~min}$ (Fig. S6B). Even when the sampling time was increased to $15 \mathrm{~h}$, the $2^{\text {nd }}$ half of the resulting chromatograms was relatively poor in peaks when compared to those obtained for dehumidifier condensed water (Fig. S6C).

Fig. 4 shows the logarithmic values of average response ratios for common compounds (sorted following their increasing retention times in the DB-WAXETR column), identified 
using both sampling approaches, at four different sampling points (S2, S3, S7 and S20, Table 1). In general, the response ratios plot follows a similar trend that the negative logarithms of the Henry's law constants $\left(\mathrm{K}_{\mathrm{H}}\right.$, atm $\left.\mathrm{m}^{3} \mathrm{~mol}^{-1}\right)$. That is, the relative extraction yield provided by dehumidifier condensed water samples increases with the decrease of the $\mathrm{K}_{H}$ values. Not surprisingly, $\mathrm{K}_{H}$ is defined as the ratio between the pressure of a given compound in the gas phase and its concentration in the equilibrium water phase. In general,

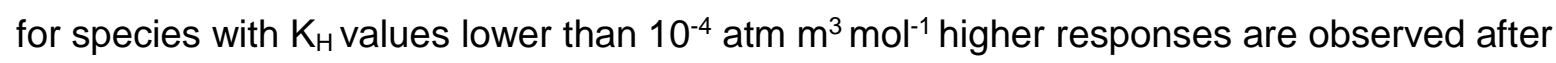
SPE of $300 \mathrm{~mL}$ of condensed water than for direct sampling of $5 \mathrm{~m}^{3}$ of air. In addition to compounds in Fig. 4, other species were only noticed using one of the two sampling techniques. For example, camphene and pinene (alpha and beta isomers), and the terpene-related species $p$-cymene were found in chromatograms corresponding to active air sampling, but not in the extracts from dehumidifier water. Their $\mathrm{K}_{H}$ values (data at

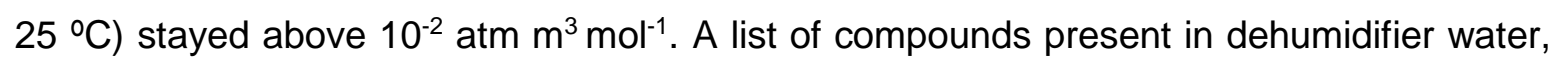
but not detected using active sampling, is provided as supplementary information, Table S3. Their $\mathrm{K}_{\mathrm{H}}$ values varied between $10^{-6}$ and $10^{-11}$ atm $\mathrm{m}^{3} \mathrm{~mol}^{-1}$.

\section{Conclusions}

The GC-EI-TOF-MS chromatograms obtained for the extracts of dehumidifier water samples contain a large number of semi-volatile compounds. Variations among sampling places, and the reasonable agreement of data obtained in the same room, with different dehumidifiers, confirm that condensed water samples are useful for qualitative analysis of the chemical composition of indoor areas. Dehumidifier appliances are portable, relatively non-expensive and non-disrupting equipment compared to pumps involved in active sampling of indoor air. The concentration efficiency of indoor air compounds in dehumidifier water is correlated with the values of their Henry constants, being effective for species with values below $10^{-4}$ atm $\mathrm{m}^{3} \mathrm{~mol}^{-1}$ at $25{ }^{\circ} \mathrm{C}$. Compounds identified in this study (including tentative identifications) represent around $25 \%$ of deconvoluted peaks in the chromatograms of dehumidifier water 
samples; therefore, construction of larger El-MS spectral databases is required to understand the complexity of the mixture of semi-volatile species existing in indoor areas.

\section{Acknowledgements}

This study was supported by Xunta de Galicia and Spanish Government through grants GRC-ED431C 2017/36 and PGC2018-094613-B-I00, both co-funded by the EU. 
Captions to figures:

Fig. 1. Deconvoluted compound chromatogram (A), accurate EI-MS spectra of selected peaks (B and C) and PCDL spectrum for a standard of benzaldehyde (D).

Fig. 2. Response ratios for compounds in condensed water samples obtained from the same room after and before installing an air freshener. A and B correspond to a selection of compounds not detected and detected in the freshener liquid, respectively.

Fig. 3. A, Chromatograms for condensed water samples obtained in the same room with two different dehumidifiers operating simultaneously. B and C, correlation plots of logarithmic responses for identified compounds in sampling places S21 and S3 using different appliances.

Fig. 4. Black, logarithmic values of response ratios for compounds identified in condensed water samples and in active sampling extracts (concentrated air volume $5 \mathrm{~m}^{3}$ ) simultaneously obtained in the same room. Average data obtained in four different places. Red, negative logarithmic values of Henry's law constant $\left(\mathrm{K}_{\mathrm{H}}\right.$, atm $\left.\mathrm{m}^{3} \mathrm{~mol}^{-1}\right)$ estimated using the bond method (values at $25^{\circ} \mathrm{C}$ ). 


\section{References}

Araki, A., Bastiaensen, M., Bamai, Y.A., Van den Eede, N., Kawai, T., Tsuboi, R., Ketema, R.M., Covaci, A., Kishi, R., 2018. Associations between allergic symptoms and phosphate flame retardants in dust and their urinary metabolites among school children. Environ. Int. 119, 438-446. https://doi.org/10.1016/i.envint.2018.07.018

Castro, G., Rodríguez, I., Ramil, M., Cela, R., 2019. Assessment of gas chromatography time-of-flight mass spectrometry for the screening of semi-volatile compounds in indoor dust. Sci. Total Environ. 688, 162-173. https://doi.org/10.1016/i.jhazmat.2015.01.043

Cecinato, A., Romagnoli, P., Perilli, M., Balducci, C., 2017. Psychotropric substances in house dusts: a preliminary assessment. Environ. Sci. Pollut. Res. 24, 21256-21261. https://doi.org/10.1007/s11356-017-9549-5

Esteve-Turrillas, F.A., Ly-Verdú, S., Pastor, A., de la Guardia, M., 2009. Development of a versatile, easy and rapid atmospheric monitor for benzene, toluene, ethylbenzene and xylenes determination in air. J. Chromatogr. A 1216, 8549-8559.

https://doi.org/10.1016/j.chroma.2009.10.001

Fromme, H., Lahrz, T., Piloty, M., Gebhart, H., Oddoy, A., Rueden, H., 2004. Occurrence of phthalates and musk fragrances in indoor air and dust from apartments and kindergartens in Berlin (Germany). Indoor Air 14, 188-195. https://doi.org/10.1111/j.1600$\underline{0668.2004 .00223 . x}$

Gale, R.W., Cranor, W.L., Alvarez, D.A., Huckins, J.N., Petty, J.D., Robertson, G.L., 2009. Semi-volatile organic compounds in residential air along the Arizona-Mexico Border, Environ. Sci. Technol. 43, 3054-3060. https://doi.org/10.1021/es803482u

Geens, T., Roosens, L., Neels, H., Covaci, A., 2009. Assessment of human exposure to Bisphenol-A, Triclosan and Tetrabromobisphenol-A through indoor dust intake in Belgium. Chemosphere 76, 755-760. https://doi.org/10.1016/j.chemosphere.2009.05.024

Glowacz-Czerwonka, D., 2017. The polyurethane foams based on melamineformaldehyde-cyclohexanone. Cell. Polym. 36, 35-50.

https://doi.org/10.1177/026248931703600103 
Gómez-Ramos, M.M., Ucles, S., Ferrer, C., Fernández-Alba, A.R., Hernando, M.D., 2019. Exploration of environmental contaminants in honeybees using GC-TOF-MS and GCOrbitrap-MS. Sci. Total Environ. 647, 232-244.

https://doi.org/10.1016/j.scitotenv.2018.08.009

Hoang, T., Castorina, R., Gaspar, F., Maddalena, R., Jenkins, P.L., Zhang, Q., McKone, T.E., Benfenati, E., Shi, A.Y., Bradman, A., 2017. VOC exposures in California early childhood education environments. Indoor Air 27, 609-621.

https://doi.org/10.1111/ina.12340

Laboire, S., Moreau-Guigon, E., Alliot, F., Desportes, A., Oziol, L., Chevreuil, M., 2016. A new analytical protocol for the determination of 62 endocrine-disrupting compounds in indoor air. Talanta 147, 132-141. https://doi.org/10.1016/j.talanta.2015.09.028

Lamas, J.P., Sánchez-Prado, L., García-Jares, C., Llompart, M., 2010. Determination of fragrance allergens in indoor air by active sampling followed by ultrasound-assisted solvent extraction and gas chromatography-mass spectrometry. J. Chromatogr. A, 1217, 1882-1890. https://doi.org/10.1016/j.chroma.2010.01.055

Liu, S., Thompson, S.L., Stark, H., Ziemann, P.J., Jimenez, J.L., 2017. Gas-phase carboxylic acids in a university classroom: abundance, variability and sources. Environ. Sci. Technol. 51, 5454-5463. https://doi.org/10.1021/acs.est.7b01358

Lucattini, L., Poma, G., Covaci, A., de Boer, J., Lamoree, J.H., Leonards, P.E.G., 2018. A review of semi-volatile organic compounds (SVOCs) in the indoor environment: occurrence in consumer products. Chemosphere 201, 466-482.

https://doi.org/10.1016/j.chemosphere.2018.02.161

Melymuk, L., Bohlin-Nizzetto, P., Vojta, Š., Krátká M., Kukučka, P., Audy, O., Přibylová, P., Klánová, J., 2016. Distribution of legacy and emerging semi-volatile organic compounds in five indoor matrices in a residential environment. Chemosphere 153, 179-186.

https://doi.org/10.1016/i.chemosphere.2016.03.012

Moniruzzaman, M., Rodríguez, I., Ramil, M., Cela, R., Sulaiman, S.A., Gan, S.H., 2014. Assessment of gas Chromatography time-of-flight accurate mass spectrometry for identification of volatile and semi-volatile compounds in honey. Talanta 129, 505-515. https://doi.org/10.1016/j.talanta.2014.06.019 
Palmiotto, G., Pieraccini, G., Moneti, G., Dolara, P., 2001. Determination of the levels of aromatic amines in indoor and outdoor air in Italy. Chemosphere 43, 355-361.

https://doi.org/10.1016/S0045-6535(00)00109-0

Pandey, S.K., Kim, K.H., 2010. A review of environmental tobacco smoke and its determination in air. Trends Anal. Chem. 29, 804-819.

https://doi.org/10.1016/j.trac.2010.04.014

Ramírez, N., Marcé, R.M., Borrull, F., 2010. Development of a thermal desorption-gas Chromatography-mass spectrometry method for determining personal care products in air.

J. Chromatogr. A 1217, 4430-4438. https://doi.org/10.1016/j.chroma.2010.04.049

Roll, I.B., Pycke, B.F.G., Halden, R.U., 2015. Indoor air condensate as a novel matrix for monitoring inhalable organic contaminants. J. Hazard. Mat. 288, 89-96.

https://doi.org/10.1016/j.jhazmat.2015.01.043

Shibuta, S., Imasaka, T., Imasaka, T., 2016. Determination of fragrance allergens by ultraviolet femtosecond laser ionization mass spectrometry. Anal. Chem. 88, 10693-10700. https://doi.org/10.1021/acs.analchem.6b03229

Soheib, M., Harner, T., 2002. Characterization and comparison of three passive air samplers for persistent organic compounds. Environ. Sci. Technol. 36, 4142-4151. https://doi.org/10.1021/es020635t

Steinemann, A., Goodman, N., 2019. Fragranced consumer products and effects on asthmatics: an international population-based study. Air Qual. Atmos. Health 12, 643-649. https://doi.org/10.1007/s11869-019-00693-w

Stupak, M., Goodall, I., Tomaniova, M., Pulkrabova, J., Hajslova, J., 2018. A novel approach to assess the quality and authenticity of Scotch whisky based on gas chromatography coupled to high resolution mass spectrometry. Anal. Chim. Acta, 1042, 60-70. https://doi.org/10.1016/j.aca.2018.09.017

Ueta, I., Takenaka, R., Fujimura, K., Narukami, S., Sasaki, T., Maeda, T., 2019. Quantitative determination of 2-ethyl-1-hexanol, Texanol and TXIB in in-door air using a solid-phase extraction-type collection device followed by gas chromatography-mass spectrometry. Anal. Sci. 35, 855-859. https://doi.org/10.2116/analsci.19P033 
Wakayama, T., Ito, Y., Sakai, K., Miyake, M., Shibata, E., Ohno, H., Kamijima, M., 2019.

Comprehensive review of 2-ethyl-1-hexanol as an indoor air pollutant. J. Occup. Health 61, 19-35. https://doi.org/10.1002/1348-9585.12017

Weschler, C. J., Nazaroff, W.W., 2014. Dermal uptake of organic vapors commonly found in indoor air. Environ. Sci. Technol. 48, 1230-1237. https://doi.org/10.1021/es405490a

Zhang, J., Zhang, X., Wu, L., Wang, T., Zhao, J., Zhang, Y., Men, Z., Mao, H., 2018.

Occurrence of benzothiazole and its derivates in tire wear, road dust, and roadside soil, Chemosphere 201, 310-317. https://doi.org/10.1016/j.chemosphere.2018.03.007 
Table 1. Codes of dehumidifier water samples, indicating the sampling place and the identities of the three most intense peaks in the GC-EITOF-MS chromatograms for their SPE extracts.

\begin{tabular}{|c|c|c|c|c|c|}
\hline $\begin{array}{l}\text { Sample } \\
\text { code }\end{array}$ & Sampling Place & Room & $\begin{array}{c}1^{\text {st }} \text { most intense } \\
\text { peak }\end{array}$ & $\begin{array}{c}2^{\text {nd }} \text { most intense } \\
\text { peak }\end{array}$ & $\begin{array}{c}3^{\text {rd }} \text { most intense } \\
\text { peak }\end{array}$ \\
\hline S1 & Home 1 & Laundry & Diethylene glycol butyl ether & Texanol & TXIB \\
\hline S2 & Home 1 & Bedroom & Diethylene glycol butyl ether & Texanol & TXIB \\
\hline S3 & Home 1 & Living room & Diethylene glycol butyl ether & Texanol & TXIB \\
\hline S4 & Home 1 & Kitchen & Alfa-Terpineol & Diethylene glycol butyl ether & Texanol \\
\hline S5 & Home 2 & Entrance & Nonanoic acid & Diisobutyl phthalate & 2-Phenoxyethanol \\
\hline S6 & Home 3 & Living room & Diisobutyl phthalate & Diethyl phthalate & $\begin{array}{l}\text { Nonanoic acid } \\
\text { Diethylene glycol butyl }\end{array}$ \\
\hline S7 & Home 4 & Living room & TCPP & Nonanoic acid & ether \\
\hline S8 & Home 4 & Office & Diethylene glycol butyl ether & TCPP & $\begin{array}{c}\text { Hexanoic acid } \\
\text { Diethylene glycol butyl }\end{array}$ \\
\hline S9 & Home 5 & Living room & 2-Phenoxyethanol & Diethyl phthalate & ether \\
\hline S10 & Home 6 & Living room & Nicotine & $\begin{array}{l}\text { Methyl Dihydrojasmonate } \\
\text { 4,7-Methano-1H-indenol, }\end{array}$ & Dodecanoic acid \\
\hline S11 & Home 7 & Laundry & Linalool & hexahydro- & 2-Phenoxyethanol \\
\hline S12 & Shopping centre & Hair dressing & 2-Phenoxyethanol & Methyl Dihydrojasmonate & Dodecanoic acid \\
\hline S13 & Home 8 & Living room & aGlycol & aGlycol & Nonanoic acid \\
\hline S14 & Administrative building 1 & Reception area & Texanol & TXIB & Diethyl phthalate \\
\hline S15 & Administrative building 2 & Office & Diethyl phthalate & Nonanoic acid & Diisobutyl phthtalate \\
\hline S16 & Administrative building 1 & Office & Benzyl alcohol & 2-Phenoxyethanol & Texanol \\
\hline S17 & Home 1 & Garage & Benzothiazole & TXIB & Texanol \\
\hline S18 & Home 9 & Garage & Benzothiazole & 2-phenoxyl ethanol & ${ }^{a}$ Glycol \\
\hline S19 & Home 10 & $\begin{array}{l}\text { Living room } \\
\text { Sample peparation }\end{array}$ & 2-Phenoxyethanol & Methyl Dihydrojasmonate & Diethyl phthalate \\
\hline S20 & Research building & laboratory & Nonanoic acid & Diisobutyl phthalate & Diethyl phthalate \\
\hline S21 & Home 11 & Living room & Texanol & Diethyl phthalate & Nonanoic acid \\
\hline
\end{tabular}


Table $2 \mathrm{~A}$. Fragrances and flavoring compounds identified in dehumidifier water samples.

\begin{tabular}{|c|c|c|c|c|c|c|c|}
\hline Compound & $\begin{array}{l}\text { Positive } \\
\text { samples }\end{array}$ & CAS number & LRI & Compound & $\begin{array}{l}\text { Positive } \\
\text { samples }\end{array}$ & CAS number & LRI \\
\hline Limonene & 4 & 5989-27-5 & 1219 & Beta-Ionone & 5 & $14901-07-6$ & 1972 \\
\hline Eucalyptol & 13 & $470-82-6$ & 1228 & 1-Dodecanol & 5 & $112-53-8$ & 1981 \\
\hline Octanal & 8 & $124-13-0$ & 1308 & Methyleugenol & 7 & $93-15-2$ & 2044 \\
\hline 3-Octanol & 5 & $589-98-0$ & 1406 & Ethyl maltol & 2 & $4940-11-8$ & 2047 \\
\hline Tetrahydrolinalool & 16 & $78-69-3$ & 1442 & Benzaldehyde, 4-methoxy & 18 & $123-11-5$ & 2065 \\
\hline 2-Octanol, 2,6-dimethyl- & 4 & $18479-57-7$ & 1456 & 4-Ethylguaiacol & 5 & $2785-89-9$ & 2073 \\
\hline 1-Heptanol & 19 & $111-70-6$ & 1471 & Lilial & 10 & $80-54-6$ & 2080 \\
\hline Dihydromyrcenol & 19 & $18479-58-8$ & 1479 & Cinnamal & 2 & $104-55-2$ & 2083 \\
\hline Camphor & 16 & $76-22-2$ & 1549 & Eugenol & 13 & $97-53-0$ & 2207 \\
\hline Linalool & 17 & $78-70-6$ & 1564 & Thymol & 13 & $89-83-8$ & 2213 \\
\hline Linalyl acetate & 2 & $115-95-7$ & 1573 & Naphthalene, 2-methoxy & 13 & $93-04-9$ & 2232 \\
\hline 1-Octanol & 17 & $111-87-5$ & 1574 & Carvacrol & 3 & $499-75-2$ & 2245 \\
\hline Bornyl acetate & 6 & $76-49-3$ & 1604 & Hexyl salicylate & 7 & $6259-76-3$ & 2247 \\
\hline Menthol & 19 & $15356-70-4$ & 1658 & Naphthalene, 2-ethoxy & 3 & $93-18-5$ & 2265 \\
\hline Alfa-terpineol & 20 & $98-55-5$ & 1719 & Piperonal & 15 & $120-57-0$ & 2279 \\
\hline Borneol & 19 & $507-70-0$ & 1726 & Methyl anthranilate & 17 & $134-20-3$ & 2283 \\
\hline Verbenone & 21 & $1196-01-6$ & 1739 & $\begin{array}{c}\text { Methyl Dihydrojasmonate } \\
\text { Galaxolide (two }\end{array}$ & 18 & $24851-98-7$ & $\begin{array}{l}2316 \\
2358\end{array}$ \\
\hline Citronellol & 11 & $106-22-9$ & 1782 & diastereomers) & 9 & $1222-05-5$ & 2365 \\
\hline Methylsalicylate & 8 & $119-36-8$ & 1815 & Alfa-Hexylcinnamaldehyde & 3 & $101-86-0$ & 2395 \\
\hline Geraniol & 9 & $106-24-1$ & 1869 & Tonalid & 5 & $21145-77-7$ & 2443 \\
\hline Alpha-isomethylionone & 4 & $127-51-5$ & 1877 & Coumarin & 21 & $91-64-5$ & 2519 \\
\hline Benzyl alcohol & 20 & $100-51-6$ & 1912 & Ethyl Vanillin & 18 & $121-32-4$ & 2570 \\
\hline 2-Phenylethanol & 21 & $60-12-8$ & 1941 & 2-Acetonaphthone & 20 & $93-08-3$ & 2601 \\
\hline 3,7-Dimethyl-7-hydroxyoctanal & 12 & $107-75-5$ & 1969 & & & & 2601 \\
\hline
\end{tabular}


Table 2 B. Summary of semi-volatile compounds identified in dehumidifier water samples, including their most relevant application.

\begin{tabular}{|c|c|c|c|c|}
\hline Compound & $\begin{array}{l}\text { Positive } \\
\text { samples }\end{array}$ & CAS number & LRI & Application \\
\hline Nicotine & 8 & $54-11-5$ & 1896 & \multirow[t]{2}{*}{ Alkaloids } \\
\hline Quinoline & 19 & $91-22-5$ & 1976 & \\
\hline Nonanoic acid* & 18 & $112-05-0$ & 2188 & Carboxylic acid \\
\hline Benzothiazole & 20 & $95-16-9$ & 1996 & Curing agent \\
\hline Tributyl phosphate & 12 & $126-73-8$ & 2141 & \multirow{3}{*}{ Flame retardants } \\
\hline TCPP & 17 & $13674-84-5$ & 2735 & \\
\hline Tris(2-chloroethyl) phosphate & 6 & $115-96-8$ & 3026 & \\
\hline Irgacure 184 & 16 & $947-19-3$ & 2684 & \multirow[t]{2}{*}{ Paint additives } \\
\hline Irgacure 651 & 18 & $24650-42-8$ & 2794 & \\
\hline Diazinone & 2 & $333-41-5$ & 2463 & \multirow{2}{*}{ Pesticides } \\
\hline Terbutryn & 3 & $886-50-0$ & 2992 & \\
\hline Ethyl benzene & 10 & $100-41-4$ & 1147 & \multirow{4}{*}{ Petrol components } \\
\hline p-Xylene & 16 & $106-42-3$ & 1155 & \\
\hline m-Xylene & 8 & $108-38-3$ & 1163 & \\
\hline o-Xylene & 10 & $95-47-6$ & 1210 & \\
\hline Ibuprofen & 4 & $15687-27-1$ & 2863 & Pharmaceutical \\
\hline $\begin{array}{c}\text { 2,2,4-Trimethyl-1,3-pentanediol } \\
\text { diisobutyrate (TXIB) }\end{array}$ & 11 & $6846-50-0$ & 1892 & \multirow{8}{*}{ Plasticizers } \\
\hline 1,2-Diacetin* & 21 & $102-62-5$ & 2096 & \\
\hline Dimethyl phthalate & 19 & $131-11-3$ & 2341 & \\
\hline Diethyl phthalate* & 20 & $84-66-2$ & 2409 & \\
\hline Triethyl citrate & 20 & $77-93-0$ & 2496 & \\
\hline Diisobutyl phthalate* & 21 & $84-69-5$ & 2577 & \\
\hline Dibutyl phthalate* & 19 & $84-74-2$ & 2735 & \\
\hline Tributyl acetylcitrate & 13 & $77-90-7$ & 2933 & \\
\hline Benzaldehyde* & 21 & $100-52-7$ & 1555 & \multirow{8}{*}{ Preservatives } \\
\hline $\begin{array}{l}\text { 5-Chloro-2-methyl-3(2H)- } \\
\text { isothiazolone }\end{array}$ & 1 & $26172-55-4$ & 2004 & \\
\hline 2-Phenoxyethanol & 19 & $122-99-6$ & 2178 & \\
\hline Benzoic acid & 6 & $65-85-0$ & 2475 & \\
\hline o-Hydroxybiphenyl & 17 & $90-43-7$ & 2658 & \\
\hline Benzyl Benzoate & 9 & $120-51-4$ & 2693 & \\
\hline $3(2 \mathrm{H})$-Isothiazolone, 2-octyl- & 8 & $26530-20-1$ & 2784 & \\
\hline Methylparaben & 10 & 99-76-3 & 3000 & \\
\hline
\end{tabular}

${ }^{*}$ Compounds also noticed in procedural blanks 
Table 2 B, cont. Summary of semi-volatile compounds identified in dehumidifier water samples, including their most significant application.

\begin{tabular}{ccccc}
\hline Compound & $\begin{array}{c}\text { Positive } \\
\text { samples }\end{array}$ & $\begin{array}{c}\text { CAS } \\
\text { number }\end{array}$ & LRI & Application \\
\hline Cyclohexanone & 17 & $108-94-1$ & 1321 & \\
Ethylene glycol butyl ether & 20 & $111-76-2$ & 1419 & \\
Furfural & 6 & $98-01-1$ & 1499 & \\
2-Ethyl-1-hexano/* & 21 & $104-76-7$ & 1502 & \\
Isophorone & 18 & $78-59-1$ & 1623 & \\
Diethylene Glycol ethyl ether & 7 & $111-90-0$ & 1638 & \\
1-Decanol & 3 & $112-30-1$ & 1775 & \\
Aniline & 9 & $62-53-3$ & 1787 & \\
Diethylene glycol monobutyl ether & 14 & $112-34-5$ & 1814 & Solvents/ intermediates \\
2-Nitrophenol & 3 & $88-75-5$ & 1850 & \\
Phenol* & 10 & $108-95-2$ & 2039 & \\
2,3-Dimethylphenol & 3 & $526-75-0$ & 2112 & \\
p-Cresol & 15 & $106-44-5$ & 2119 & \\
4-Ethylphenol & 18 & $123-07-9$ & 2208 & \\
Epsilon-Caprolactam & 1 & $105-60-2$ & 2225 & \\
4-chloro-3-methylphenol & 19 & $59-50-7$ & 2548 & \\
Benzoic acid, p-tert-butyl- & 20 & $98-73-7$ & 2794 & \\
Phthalimide & 13 & $85-41-6$ & 2985 & \\
\hline Dibromochloromethane & 4 & $124-48-1$ & 1322 & Trihalomethane \\
\hline
\end{tabular}

*Compounds also noticed in procedural blanks 
Table 3. Compounds tentatively identified in dehumidifier water samples, including the accurate $\mathrm{m} / \mathrm{z}$ values of two intense ions with mass errors.

\begin{tabular}{|c|c|c|c|c|c|c|c|c|c|c|}
\hline Compound & Formula & $\begin{array}{c}\text { CAS } \\
\text { number }\end{array}$ & $\begin{array}{c}\text { Experimental } \\
\text { LRI }\end{array}$ & $\begin{array}{c}\text { Literature } \\
\text { LRI }\end{array}$ & Chemical class & $\begin{array}{l}\text { Positive } \\
\text { samples }\end{array}$ & 1st ion & 2nd ion & $\begin{array}{c}\text { Mass } \\
\text { error } \\
\text { (mDa) } \\
1^{\text {st }} \text { ion }\end{array}$ & $\begin{array}{l}\text { Mass } \\
\text { error } \\
(\mathrm{mDa}) \\
2^{\text {nd }} \text { ion } \\
\end{array}$ \\
\hline Pyridine, 3-ethenyl & $\mathrm{C}_{7} \mathrm{H}_{7} \mathrm{~N}$ & $1121-55-7$ & 1501 & & Alkaloids & 5 & 105.0575 & 78.0459 & 0.3 & -0.4 \\
\hline Nicotyrine & $\mathrm{C}_{10} \mathrm{H}_{10} \mathrm{~N}_{2}$ & $487-19-4$ & 2368 & & & 5 & 158.0844 & 130.0657 & 0.4 & 0.2 \\
\hline 2-Butene, 2-methyl- & $\mathrm{C}_{5} \mathrm{H}_{10}$ & $513-35-9$ & 1259 & & \multirow{4}{*}{ Alkanes } & 6 & 70.078 & 55.0542 & 0.3 & -0.1 \\
\hline Cyclobutane, ethyl- & $\mathrm{C}_{6} \mathrm{H}_{12}$ & $4806-61-5$ & 1363 & & & 10 & 69.0701 & 56.0625 & 0.3 & 0.4 \\
\hline Isopropylcyclobutane & $\mathrm{C}_{7} \mathrm{H}_{14}$ & $872-56-0$ & 1467 & & & 17 & 83.0853 & 70.0775 & -0.3 & -0.3 \\
\hline Cyclopentane, 1,1-dimethyl- & $\mathrm{C}_{7} \mathrm{H}_{14}$ & $1638-26-2$ & 1570 & & & 8 & 83.0852 & 69.0699 & -0.4 & 0.1 \\
\hline Benzene, (1-methoxypropyl)- & $\mathrm{C}_{10} \mathrm{H}_{14} \mathrm{O}$ & $59588-12-4$ & 1783 & \multirow{9}{*}{$1820^{\mathrm{a}}$} & \multirow{9}{*}{ Benzene derivatives } & 4 & 121.0646 & 91.0543 & -0.2 & 0.1 \\
\hline 1-phenyl ethanol & $\mathrm{C}_{8} \mathrm{H}_{10} \mathrm{O}$ & 98-85-1 & 1838 & & & 5 & 122.0724 & 107.0488 & -0.3 & -0.4 \\
\hline 1-(4-tert-Butylphenyl)propan-2-one & $\mathrm{C}_{13} \mathrm{H}_{18} \mathrm{O}$ & $81561-77-5$ & 2047 & & & 5 & 190.1373 & 175.1137 & 1.5 & 1.4 \\
\hline 1-Phenoxypropan-2-ol & $\mathrm{C}_{9} \mathrm{H}_{12} \mathrm{O}_{2}$ & $770-35-4$ & 2073 & & & 8 & 152.0836 & 94.0409 & 0.4 & -0.4 \\
\hline N-methyl phthalimide & $\mathrm{C}_{9} \mathrm{H}_{7} \mathrm{NO}_{2}$ & $550-44-7$ & 2328 & & & 4 & 161.0495 & 132.0474 & 1.8 & 2.5 \\
\hline Benzene, (3-methylcyclopentyl)- & $\mathrm{C}_{12} \mathrm{H}_{16}$ & $5078-75-1$ & 2345 & & & 6 & 160.1257 & 131.0861 & 1.0 & 0.6 \\
\hline Dibenzyl ether & $\mathrm{C}_{14} \mathrm{H}_{14} \mathrm{O}$ & $103-50-4$ & 2423 & & & 13 & 92.0617 & 91.0546 & -0.3 & 0.3 \\
\hline 1,2-Ethanediol, monobenzoate & $\mathrm{C}_{9} \mathrm{H}_{10} \mathrm{O}_{3}$ & $94-33-7$ & 2554 & & & 6 & 123.0449 & 105.0344 & 0.8 & 0.9 \\
\hline Diphenyl methanol & $\mathrm{C}_{13} \mathrm{H}_{12} \mathrm{O}$ & $91-01-0$ & 2803 & & & 4 & 184.0904 & 105.0355 & 1.6 & 1.5 \\
\hline 2-(Methylmercapto)benzothiazole & $\mathrm{C}_{8} \mathrm{H}_{7} \mathrm{NS}_{2}$ & $615-22-5$ & 2484 & $2422^{\mathrm{a}}$ & $\begin{array}{c}\text { Benzothiazole } \\
\text { derivative }\end{array}$ & 4 & 181.0012 & 148.0217 & -0.3 & 0.2 \\
\hline Hexanoic acid & $\mathrm{C}_{6} \mathrm{H}_{12} \mathrm{O}_{2}$ & $142-62-1$ & 1865 & $1851^{a}$ & \multirow{5}{*}{ Carboxylic acids } & 7 & 87.0437 & 73.0277 & -0.4 & -0.6 \\
\hline Heptanoic acid & $\mathrm{C}_{7} \mathrm{H}_{14} \mathrm{O}_{2}$ & $111-14-8$ & 1972 & $1971^{a}$ & & 8 & 101.0596 & 87.0438 & -0.2 & -0.3 \\
\hline Octanoic acid & $\mathrm{C}_{8} \mathrm{H}_{16} \mathrm{O}_{2}$ & $124-07-2$ & 2079 & $2086^{a}$ & & 17 & 101.0592 & 87.0438 & -0.6 & -0.3 \\
\hline n-Decanoic acid & $\mathrm{C}_{10} \mathrm{H}_{20} \mathrm{O}_{2}$ & $334-48-5$ & 2292 & $2275^{a}$ & & 4 & 129.0911 & 115.0753 & 0.1 & -0.1 \\
\hline Tetradecanoic acid & $\mathrm{C}_{14} \mathrm{H}_{28} \mathrm{O}_{2}$ & $544-63-8$ & 2716 & $2716^{a}$ & & 6 & 185.154 & 129.0914 & 0.4 & 0.4 \\
\hline
\end{tabular}


Table 3 cont. Compounds tentatively identified in dehumidifier water samples, including the accurate $\mathrm{m} / \mathrm{z}$ values of two intense ions with mass errors.

\begin{tabular}{|c|c|c|c|c|c|c|c|c|c|c|}
\hline Compound & Formula & $\begin{array}{c}\text { CAS } \\
\text { number }\end{array}$ & $\begin{array}{c}\text { Experimental } \\
\text { LRI }\end{array}$ & $\begin{array}{c}\text { Literature } \\
\text { LRI }\end{array}$ & $\begin{array}{c}\text { Chemical } \\
\text { class }\end{array}$ & $\begin{array}{l}\text { Positive } \\
\text { samples }\end{array}$ & $1^{\text {st }}$ ion & $2^{\text {nd }}$ ion & $\begin{array}{l}\text { Mass } \\
\text { error } \\
\text { (mDa) } \\
\text { 1st ion }\end{array}$ & $\begin{array}{l}\text { Mass } \\
\text { error } \\
\text { (mDa) } \\
\text { 2nd ion }\end{array}$ \\
\hline Butanoic acid, ethyl ester & $\mathrm{C}_{6} \mathrm{H}_{12} \mathrm{O}_{2}$ & $105-54-4$ & 1071 & $1041^{\mathrm{a}}$ & \multirow{6}{*}{ Esters } & 3 & 101.0615 & 88.0536 & 1.2 & 1.2 \\
\hline Butanedioic acid, dimethyl ester & $\mathrm{C}_{6} \mathrm{H}_{10} \mathrm{O}_{4}$ & $106-65-0$ & 1616 & $1595^{a}$ & & 10 & 115.0384 & 87.0441 & -0.6 & 0.1 \\
\hline Hexanedioic acid, dimethyl ester & $\mathrm{C}_{8} \mathrm{H}_{14} \mathrm{O}_{4}$ & $627-93-0$ & 1842 & $1819^{a}$ & & 10 & 143.0708 & 114.0675 & 0.5 & -0.1 \\
\hline $\begin{array}{l}\text { Hexanoic acid, 2-ethyl- } \\
\text { 3-hydroxy-2,2,4-trimethylpentyl }\end{array}$ & $\mathrm{C}_{8} \mathrm{H}_{16} \mathrm{O}_{2}$ & $149-57-5$ & 1968 & $1963^{a}$ & & 8 & 101.0594 & 88.0515 & -0.4 & -0.4 \\
\hline isobutyrate (Texanol) & $\mathrm{C}_{12} \mathrm{H}_{24} \mathrm{O}_{3}$ & $\begin{array}{c}77-68-9 \\
1000373-\end{array}$ & 1889, 1909 & & & 9 & 173.1168 & 89.0593 & -0.5 & -0.5 \\
\hline Isobutyl methyl phthalate & $\mathrm{C}_{13} \mathrm{H}_{16} \mathrm{O}_{4}$ & 89-3 & 2476 & & & 3 & 163.0391 & 149.0235 & 0.2 & 0.2 \\
\hline $\begin{array}{l}\text { 2(3H)-Furanone, 5-ethenyldihydro- } \\
\text { 5-methyl- }\end{array}$ & $\mathrm{C}_{7} \mathrm{H}_{10} \mathrm{O}_{2}$ & $1073-11-6$ & 1703 & $1689^{a}$ & Furane & 4 & 111.0431 & 98.0363 & -0.9 & 0.1 \\
\hline $\begin{array}{l}\text { 2-Propanol, 1-butoxy- } \\
\text { 1-Propanol, 2-(2- }\end{array}$ & $\mathrm{C}_{7} \mathrm{H}_{16} \mathrm{O}_{2}$ & $5131-66-8$ & 1354 & $1364^{\mathrm{a}}$ & \multirow{4}{*}{ Glycols } & 14 & 87.0805 & 57.0696 & 0.1 & -0.3 \\
\hline $\begin{array}{l}\text { methoxypropoxy)- } \\
\text { 1,3-Pentanediol, 2,2,4-trimethyl- }\end{array}$ & $\mathrm{C}_{7} \mathrm{H}_{16} \mathrm{O}_{3}$ & $13588-28-8$ & 1584 & & & 3 & 117.0916 & 73.0644 & 0.6 & -0.4 \\
\hline $\begin{array}{c}\text { isobutyrate } \\
\text { Ethanol 2-[2-(2- }\end{array}$ & $\mathrm{C}_{8} \mathrm{H}_{18} \mathrm{O}_{2}$ & $144-19-4$ & 1947 & & & 6 & 85.0646 & 73.0644 & -0.2 & -0.4 \\
\hline butoxyethoxy)ethoxy]- & $\mathrm{C}_{10} \mathrm{H}_{22} \mathrm{O}_{4}$ & $143-22-6$ & 2217 & & & 4 & 85.0649 & 57.0697 & 0.2 & -0.2 \\
\hline 1H-Inden-1-one, 2,3-dihydro- & $\mathrm{C}_{9} \mathrm{H}_{8} \mathrm{O}$ & 83-33-0 & 2055 & & Indene & 17 & 132.0583 & 104.0626 & 1.3 & 0.5 \\
\hline Indole & $\mathrm{C}_{8} \mathrm{H}_{7} \mathrm{~N}$ & $120-72-9$ & 2496 & $2445^{a}$ & Indole & 2 & 117.0585 & 90.0471 & 1.2 & 0.7 \\
\hline Tri-ethyl phosphate & $\mathrm{C}_{6} \mathrm{H}_{15} \mathrm{O}_{4} \mathrm{P}$ & $78-40-0$ & 1675 & $1672^{\mathrm{a}}$ & Organophosphate & 21 & 155.0469 & 127.0158 & 0.1 & 0.4 \\
\hline 1H-Pyrrole-2-carboxaldehyde & $\mathrm{C}_{5} \mathrm{H}_{5} \mathrm{NO}$ & $1003-29-8$ & 2062 & $2044^{a}$ & Pyrrole derivative & 3 & 95.0374 & 94.029 & 0.8 & 0.3 \\
\hline \multirow{3}{*}{$\begin{array}{c}\text { cis-Furanoid linalool oxide } \\
\text { trans-Furanoid linalool oxide } \\
\text { 3-Cyclohexen-1-ol, 1-methyl-4-(1- } \\
\text { methylethyl)- }\end{array}$} & $\mathrm{C}_{10} \mathrm{H}_{18} \mathrm{O}_{2}$ & $5989-33-3$ & 1460 & $1462^{\mathrm{b}}$ & \multirow{4}{*}{ Terpenoids } & 7 & 111.0799 & 94.0774 & -0.5 & -0.4 \\
\hline & $\mathrm{C}_{10} \mathrm{H}_{18} \mathrm{O}_{2}$ & $34995-77-2$ & 1489 & $1483^{a}$ & & 5 & 111.0803 & 94.0778 & -0.2 & 0.1 \\
\hline & $\mathrm{C}_{10} \mathrm{H}_{18} \mathrm{O}$ & $586-82-3$ & 1593 & $1589^{a}$ & & 9 & 136.1244 & 121.1012 & -0.3 & 0.1 \\
\hline L-.alpha.-Terpineol & $\mathrm{C}_{10} \mathrm{H}_{18} \mathrm{O}$ & $10482-56-1$ & 1718 & $1722^{\mathrm{b}}$ & & 14 & 136.1247 & 121.1014 & 0.1 & 0.3 \\
\hline
\end{tabular}




\begin{tabular}{cccccccc}
\hline $\begin{array}{c}\text { Cyclohexanol, 4-(1,1- } \\
\text { dimethylethyl)-, trans- }\end{array}$ & $\mathrm{C}_{10} \mathrm{H}_{20} \mathrm{O}$ & $21862-63-5$ & 1766 & & 6 & 123.1187 & 81.071 \\
$\begin{array}{c}\text { 4,7-Methano-1H-indenol, } \\
\text { hexahydro- }\end{array}$ & $\mathrm{C}_{10} \mathrm{H}_{14} \mathrm{O}$ & $37275-49-3$ & 2009 & & 1.3 & 0.6 \\
$\begin{array}{c}\text { 2,6-Di-tert-butyl-4-hydroxy-4- } \\
\text { methylcyclohexa-2,5-dien-1-one }\end{array}$ & $\mathrm{C}_{15} \mathrm{H}_{24} \mathrm{O}_{2}$ & $10396-80-2$ & 2118 & $2049^{\mathrm{a}}$ & 132.0939 & 117.0704 & 0.5 \\
\hline
\end{tabular}

aLRI values obtained from ChemSpider database (http://www.chemspider.com/) for Carbowax-type GC columns.

bLRI obtained from Moniruzzaman et al., 2014. 

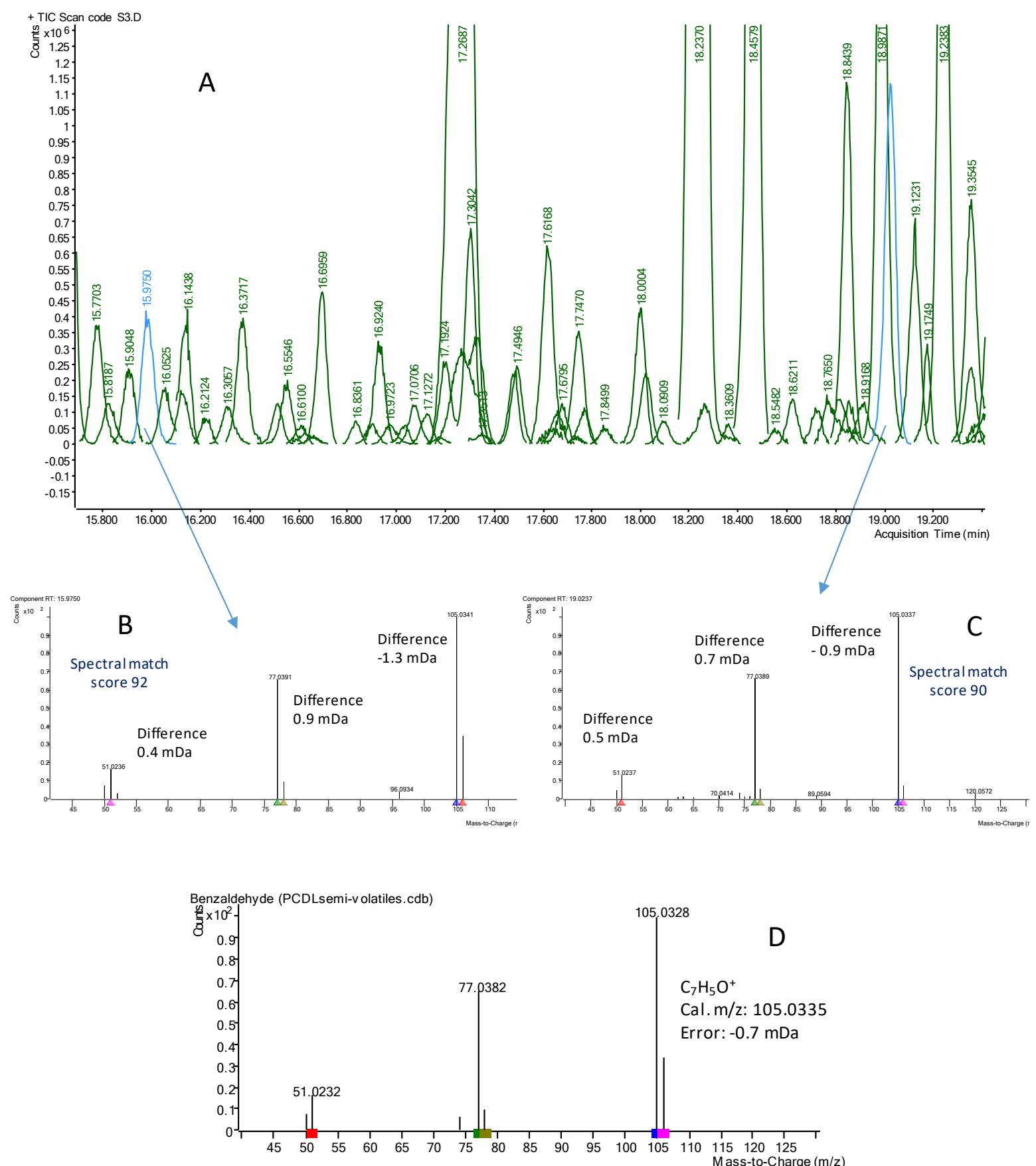

Fig. 1 

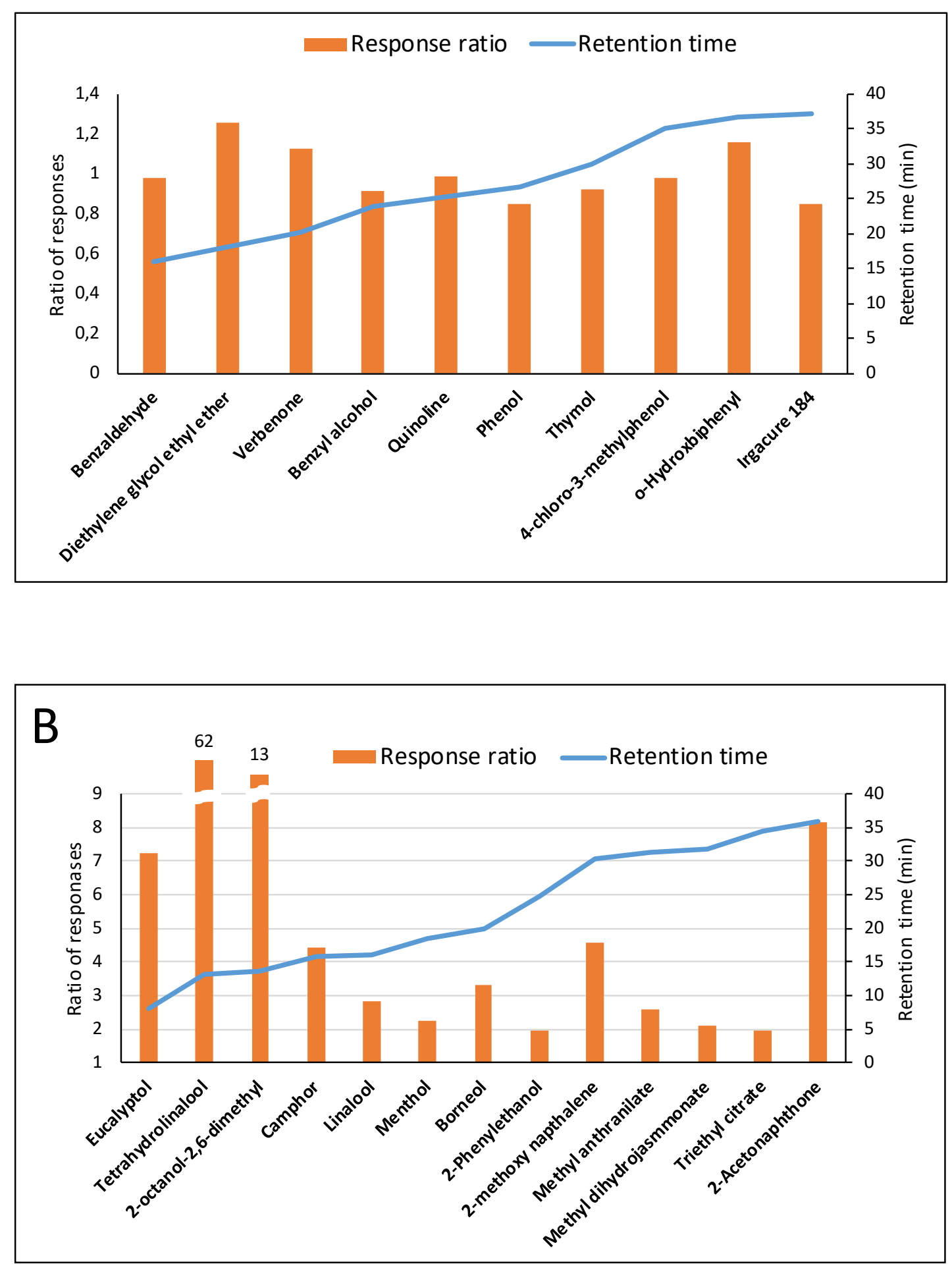

Fig. 2 

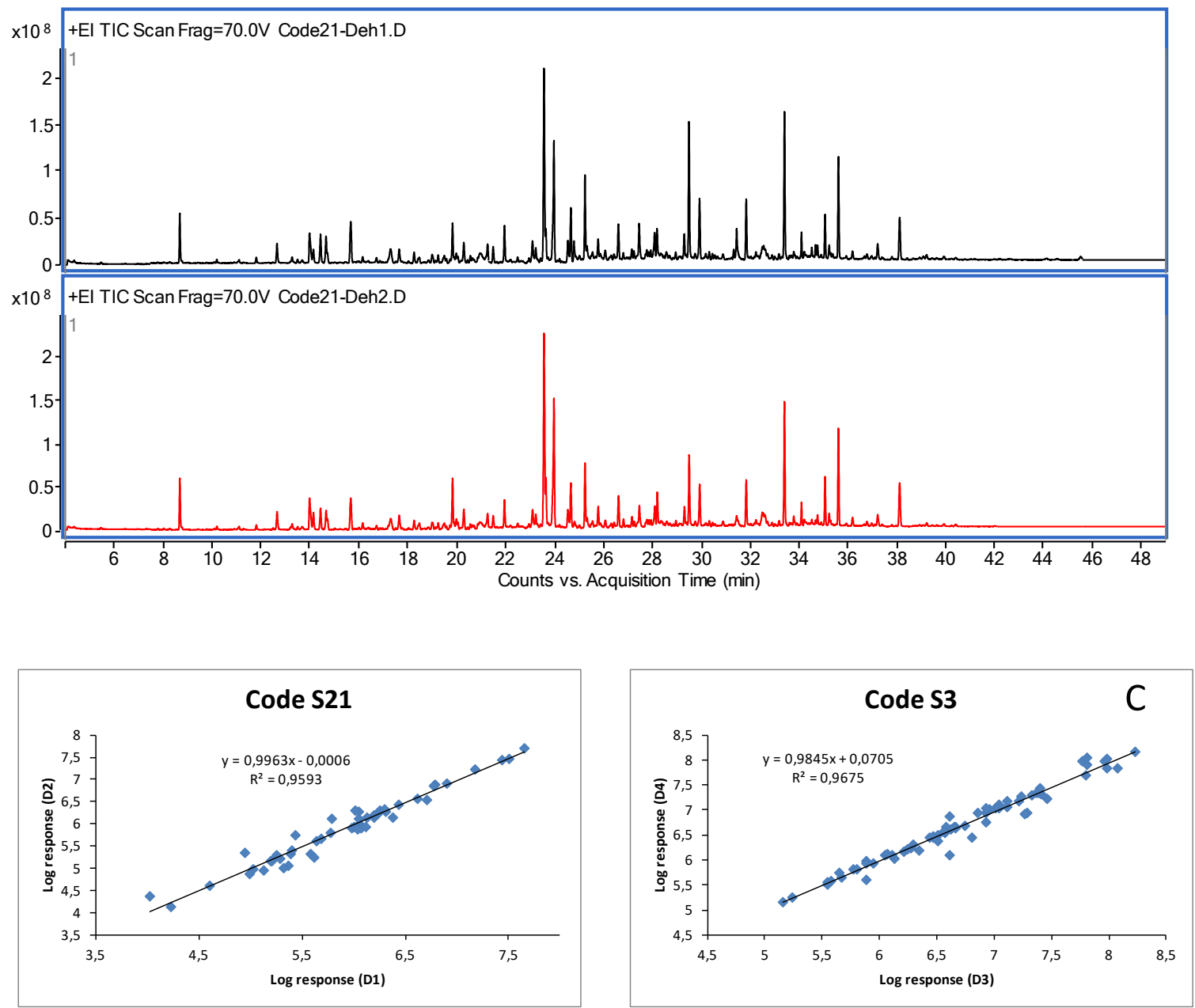

Fig. 3 


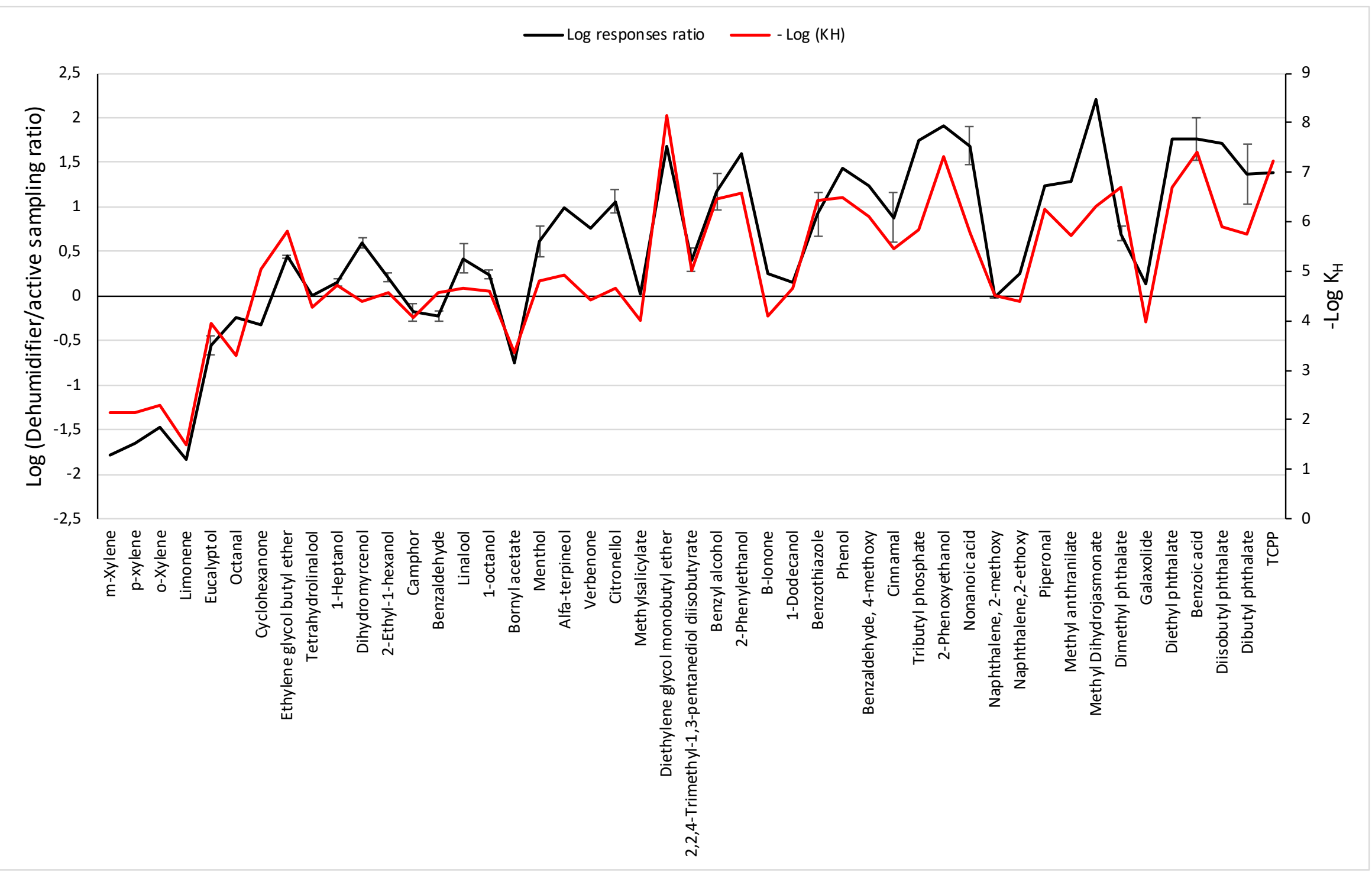

Fig. 4 
Supplementary information to manuscript:

Portable dehumidifiers condensed water: a novel matrix for the screening of semi-volatile compounds in indoor air

M. Cobo, M. Ramil, R. Cela, I. Rodríguez*

Department of Analytical Chemistry, Nutrition and Food Sciences. Institute of Research

on Chemical and Biological Analysis (IAQBUS). Universidade de Santiago de

Compostela, 15782-Santiago de Compostela, Spain.

${ }^{*}$ corresponding author

e-mail: isaac.rodriguez@usc.es 
Table S1. Data corresponding to sampling places, temperature and relative humidity before dehumidifier operation.

\begin{tabular}{|c|c|c|c|c|c|}
\hline Sample code & Dehumidifier system & Room volume $\left(\mathrm{m}^{3}\right)$ & Temperature (ㄷ) & Relative air humidity (\%) & $\begin{array}{l}\text { Volume of the } \\
\text { condensed water } \\
\text { sample (mL) }\end{array}$ \\
\hline S1 & 1 & 46 & 21 & 72 & 650 \\
\hline S2 & 1 & 55 & 19 & 68 & 680 \\
\hline S3 & 1 & 90 & 19 & 68 & 700 \\
\hline S4 & 1 & 30 & 21 & 68 & 520 \\
\hline S5 & 1 & 50 & 18 & 65 & 800 \\
\hline S6 & 1 & 33 & 18 & 72 & 700 \\
\hline S7 & 1 & 53 & 21 & 62 & 1000 \\
\hline S8 & 1 & 25 & 22 & 65 & 850 \\
\hline S9 & 1 & 55 & 19 & 81 & 1000 \\
\hline S10 & 1 & 65 & 20 & 84 & 1000 \\
\hline S11 & 2 & 25 & 20 & 80 & 900 \\
\hline S12 & 1 & 105 & 22 & 56 & 400 \\
\hline S13 & 1 & 75 & 22 & 70 & 600 \\
\hline S14 & 1 & 35 & 20 & 75 & 500 \\
\hline S15 & 1 & 60 & 23 & 75 & 1900 \\
\hline S16 & 1 & 70 & 19 & 65 & 600 \\
\hline S17 & 1 & 150 & 16 & 75 & 1200 \\
\hline S18 & 3 & 150 & 17 & 75 & 1500 \\
\hline S19 & 4 & 35 & 19 & 80 & 600 \\
\hline S20 & 1 & 400 & 21 & 62 & 2000 \\
\hline S21 & 5 & 35 & 22 & 85 & 800 \\
\hline
\end{tabular}


Table S2. Summary of compounds, including their retention times and a representative ion, used to investigate potential breakthrough problems during active sampling of indoor air in the HLB cartridge.

\begin{tabular}{|c|c|c|}
\hline Compound & ${ }^{\mathrm{a}}$ Retention time (min) & $\begin{array}{c}\text { Representative ion } \\
(\mathrm{m} / \mathrm{z})\end{array}$ \\
\hline Limonene & 7.81 & 93.0701 \\
\hline Eucalyptol & 8.01 & 154.1354 \\
\hline Gamma-Terpinene & 8.85 & 136.1252 \\
\hline Cymene & 9.51 & 119.0847 \\
\hline Camphor & 15.77 & 152.1195 \\
\hline Linalool & 16.14 & 121.1017 \\
\hline Borneol acetate & 17.17 & 136.1247 \\
\hline Neral & 19.57 & 137.096 \\
\hline Alfa-Terpineol & 19.84 & 121.1007 \\
\hline Verbenone & 20.3 & 135.0801 \\
\hline Citral & 20.71 & 137.096 \\
\hline Citronellol & 21.26 & 95.0854 \\
\hline Geraniol & 23.07 & 123.1176 \\
\hline Eugenol & 29.78 & 164.0835 \\
\hline Thymol & 29.77 & 135.0799 \\
\hline Carvacrol & 30.54 & 135.0797 \\
\hline
\end{tabular}

Values corresponding to the DB-WAXETR column. 
Table S3. Summary of compounds identified in condensed water extracts, and not detected after active sampling of $5 \mathrm{~m}^{3}$ of indoor air. Henry's law constant values $\left(\mathrm{K}_{H}\right)$ predicted using the bond method (http://www.chemspider.com/).

\begin{tabular}{|c|c|}
\hline Compound & 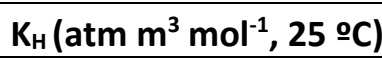 \\
\hline 1,2-Diacetin & $2.60 \mathrm{e}-11$ \\
\hline 2-Acetonaphthone & $9.58 \mathrm{e}-7$ \\
\hline 4-chloro-3-methylphenol & $4.58 \mathrm{e}-7$ \\
\hline 4-ethylphenol & $8.21 \mathrm{e}-7$ \\
\hline Coumarin & $6.95 e-6$ \\
\hline Ethyl Vanillin & $1.1 \mathrm{e}-10$ \\
\hline Irgacure 184 & $2.78 e-6$ \\
\hline Isophorone & ${ }^{a} 6.64 e-6$ \\
\hline Phthalimide & $1.02 \mathrm{e}-8$ \\
\hline Quinoline & a1.67e-6 \\
\hline Tributyl acetylcitrate & $3.78 \mathrm{e}-10$ \\
\hline Triethyl citrate & а3.84e-9 \\
\hline Vanillin & a $2.15 \mathrm{e}-9$ \\
\hline
\end{tabular}

aExerimental values. 


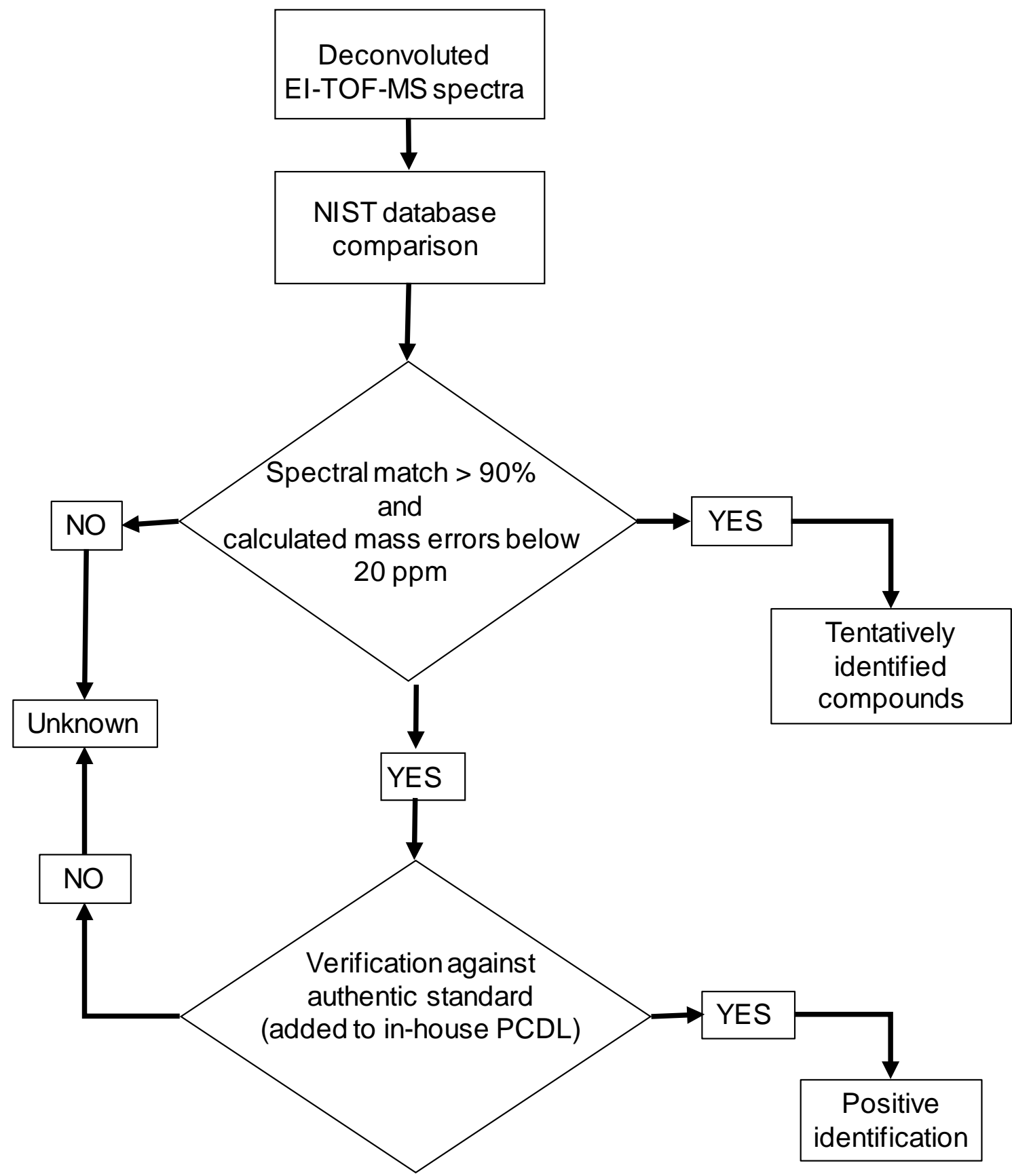

Fig. S1. Scheme of the workflow employed for non-target data mining of compounds existing in indoor air related samples. 

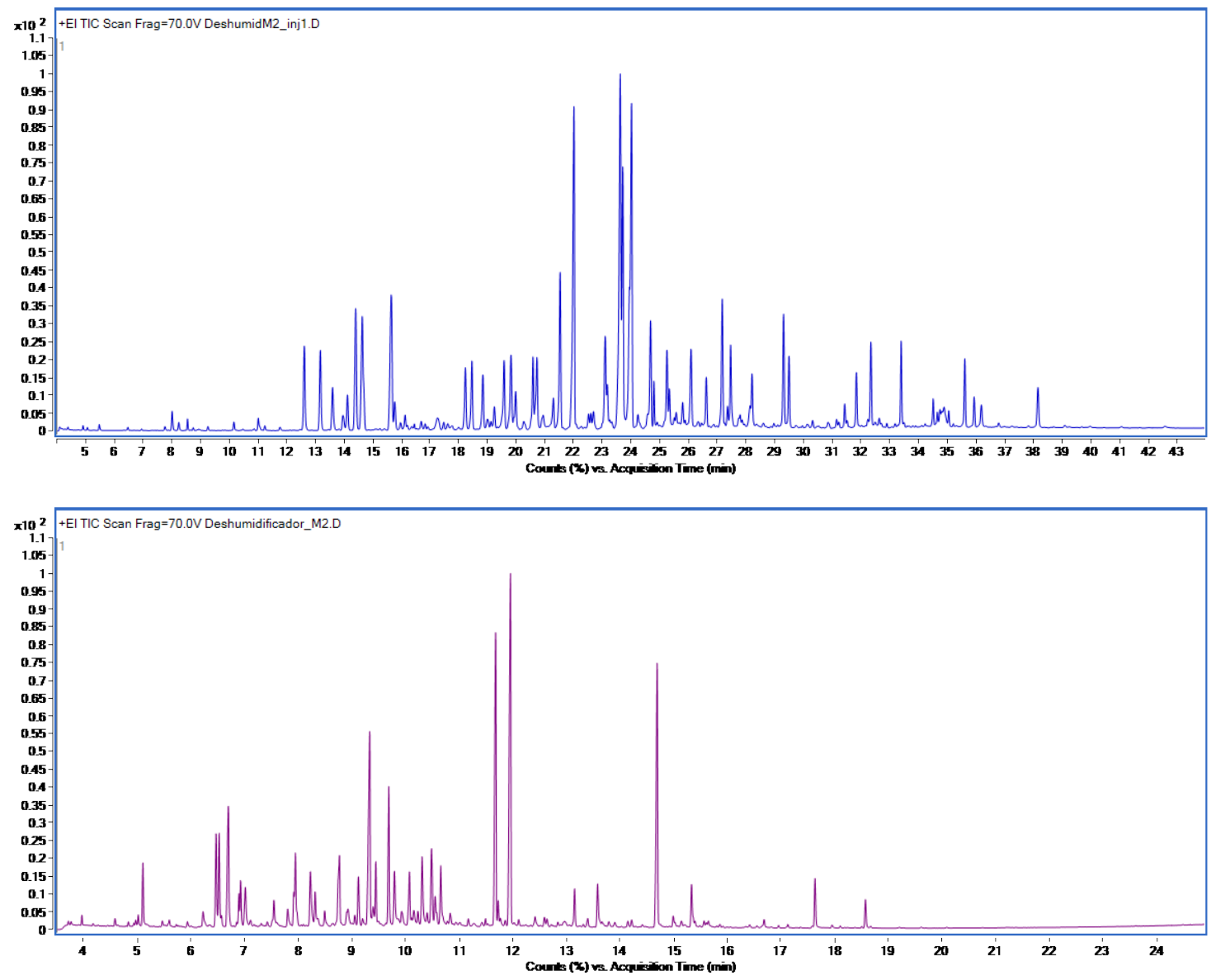

Fig. S2. GC-EI-TOF-MS chromatograms for the same SPE extract from dehumidifier water injected in the DB-WAXETR (A) and the BP-5 (B) column. DBP, dibutyl phthalate. 

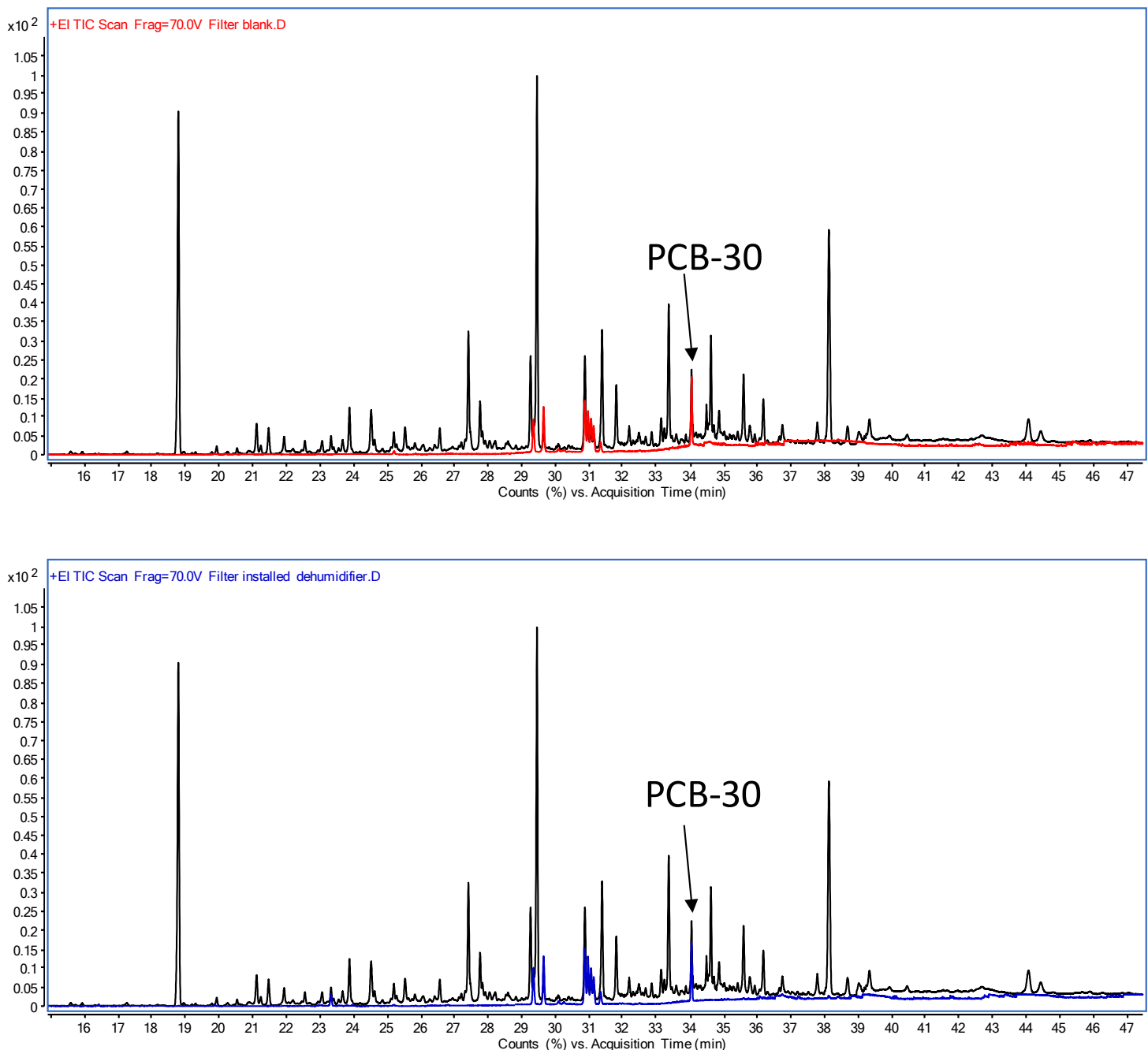

Fig. S3. Chromatograms obtained for condensed dehumidifier water (black), a blank of glass fiber filter (red), and a glass fiber filter placed before the coarse grid of the dehumidifier (blue) while collected the condensed water sample. Peaks in glass fiber filter extracts were tentatively identified as diisopropyl naphthalene isomers. 

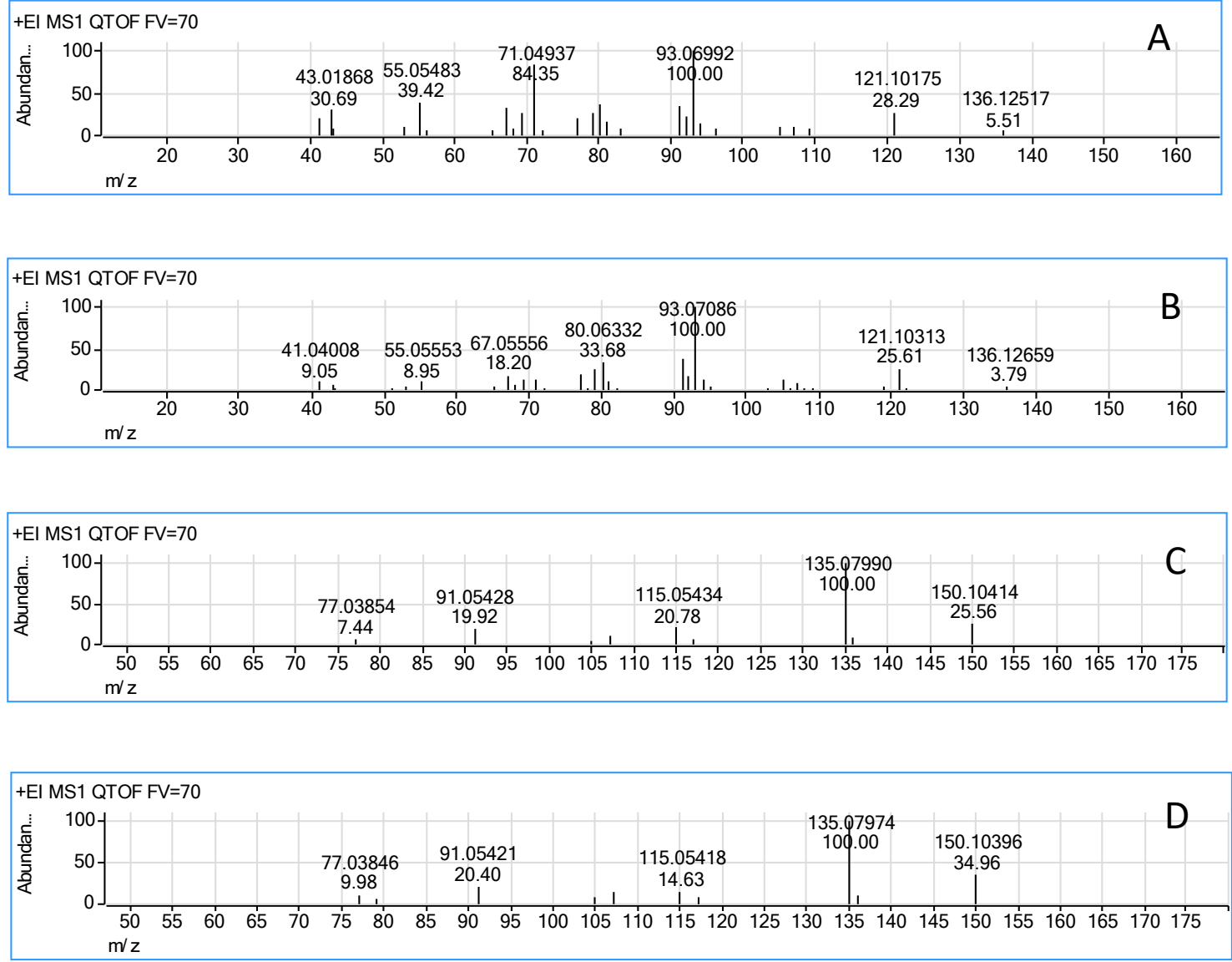

Fig. S4. Accurate El-MS spectra for pairs of related species. $A$ and $B$, Linalool $\left(\mathrm{C}_{10} \mathrm{H}_{18} \mathrm{O}\right)$ and Linalyl acetate $\left(\mathrm{C}_{12} \mathrm{H}_{20} \mathrm{O}_{2}\right) . \mathrm{C}$ and $\mathrm{D}$, Thymol $\left(\mathrm{C}_{10} \mathrm{H}_{14} \mathrm{O}\right)$ and Carvacrol $\left(\mathrm{C}_{10} \mathrm{H}_{14} \mathrm{O}\right)$. Figures under $\mathrm{m} / \mathrm{z}$ values correspond to the relative intensity of each ion. 


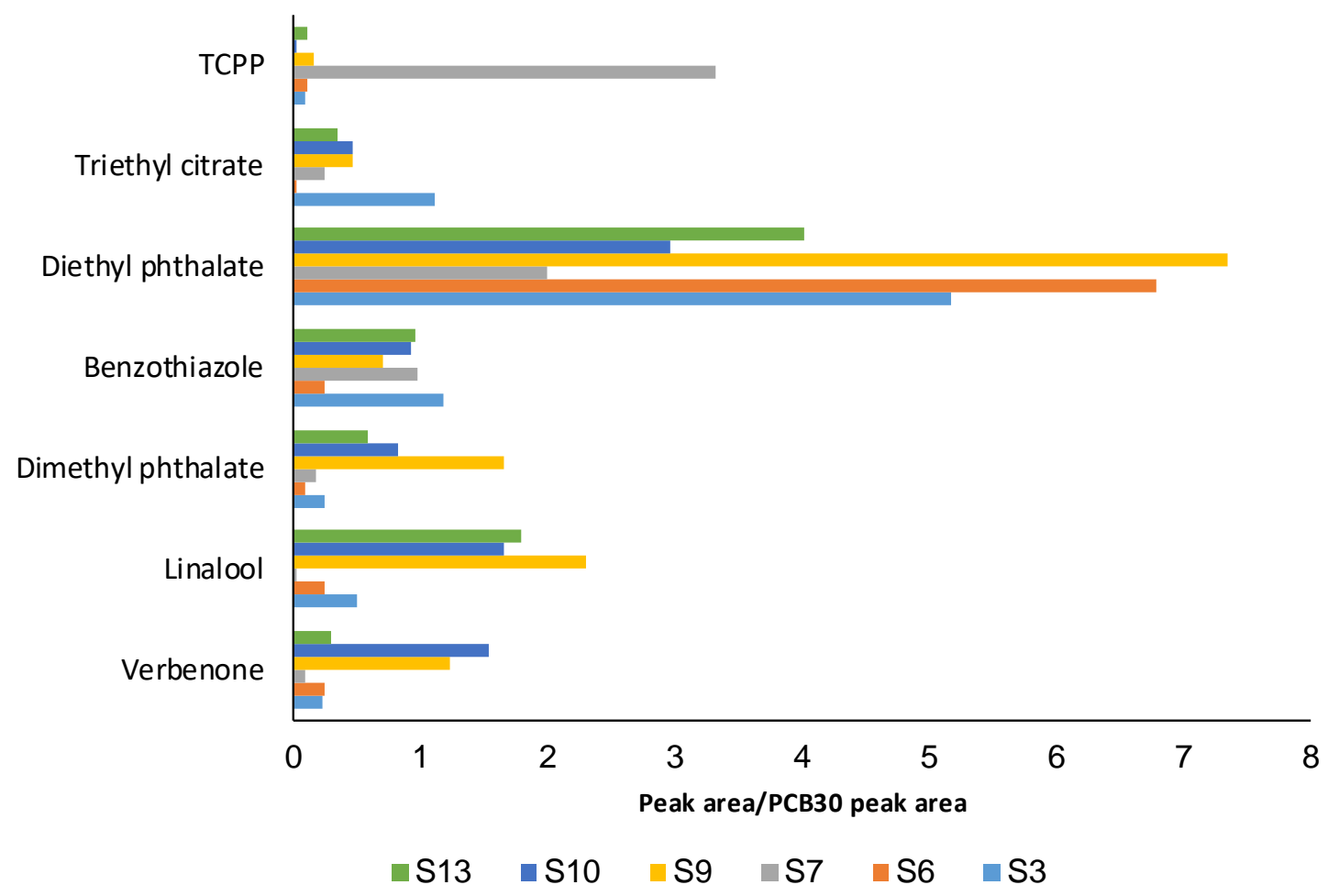

Fig. S5. Corrected responses (deconvoluted compound peak area/PCB 30 peak area) for selected compounds in the living room of different homes. Data corresponding to water samples obtained with the same dehumidifier. 

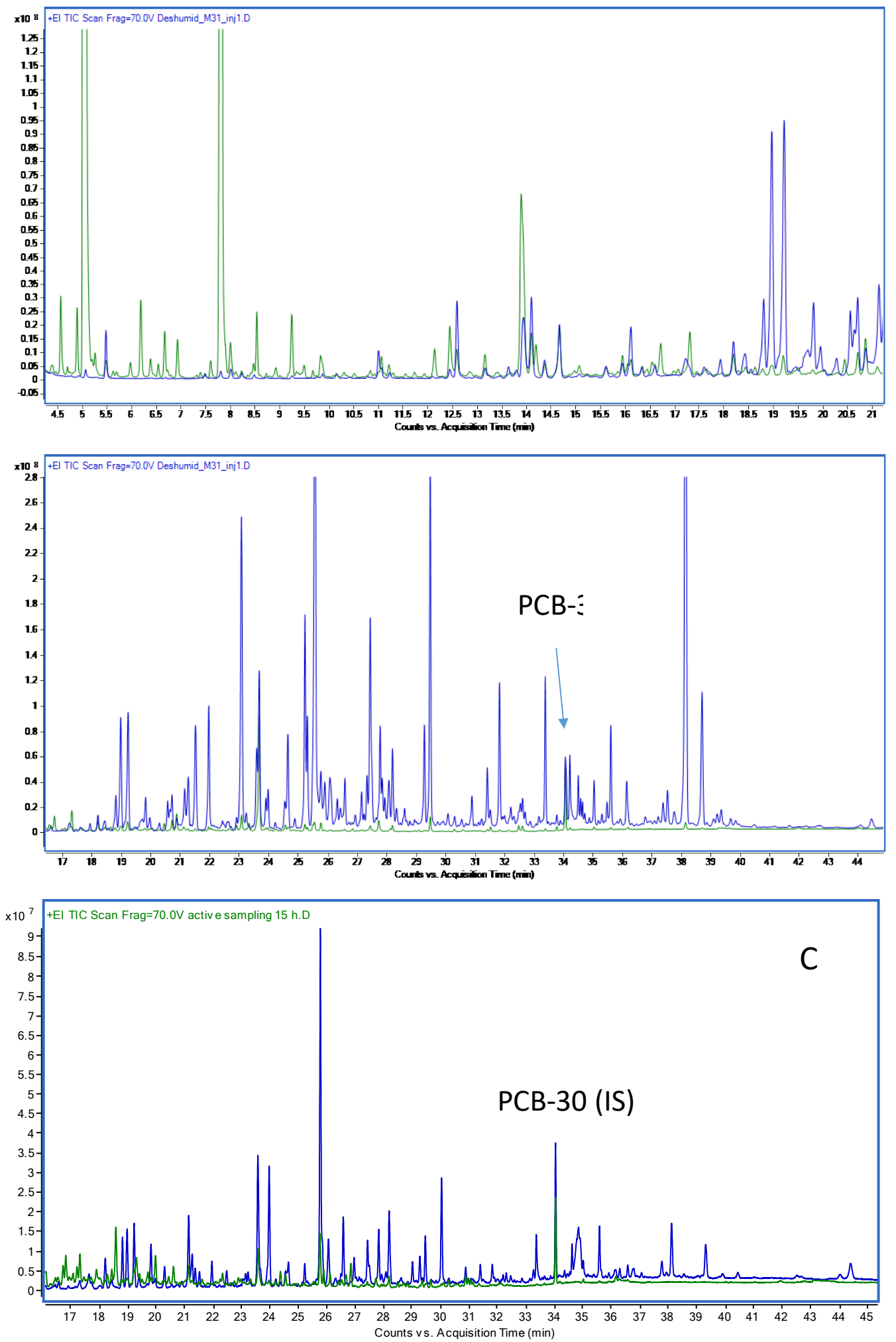

Fig. S6. GC-El-TOF-MS chromatograms corresponding to active sampling (green) for $5 \mathrm{~h}$ at $16.5 \mathrm{~L}$ $\mathrm{min}^{-1}$ and the SPE extract from the dehumidifier water sample (blue) simultaneously obtained from the same room. A, retention time interval: 4-21 $\mathrm{min}$. B, retention time range: 16-45 $\mathrm{min}$. C, chromatograms after $15 \mathrm{~h}$ of active sampling (green) versus analysis of dehumidifier water (blue) obtained in a different room. Pairs of chromatograms are shown in the same scale. 